\title{
Effects of Multispecies Probiotic on Intestinal Microbiota and Mucosal Barrier Function of Neonatal Calves Infected With E. coli K99
}

\author{
Yanyan Wu' ${ }^{1}$, Cunxi Nie', Ruiqing Luo ${ }^{2}$, Fenghua ${ }^{1}{ }^{1}$, Xue Bai ${ }^{1}$, Hongli Chen ${ }^{2}$, Junli Niu ${ }^{1}$, \\ Chen Chen ${ }^{1}$ and Wenju Zhang ${ }^{1 *}$ \\ ${ }^{1}$ College of Animal Science and Technology, Shihezi University, Shihezi, China, ${ }^{2}$ Xinjiang Tianshan Junken Animal Husbandry \\ Co., Ltd., Shihezi, China
}

OPEN ACCESS

Edited by:

Yigang Xu,

Zhejiang A\&F University, China

Reviewed by:

Gui-Lian Yang,

Jilin Agricultural University, China

Lili Wang,

Dalian University of Technology, China

*Correspondence:

Wenju Zhang

zhangwj1022@sina.com

Specialty section:

This article was submitted to

Microbial Immunology,

a section of the journal

Frontiers in Microbiology

Received: 11 November 2021

Accepted: 25 November 2021

Published: 26 January 2022

Citation:

Wu Y, Nie C, Luo R, Qi F, Bai X,

Chen $H$, Niu J, Chen $C$ and Zhang $W$ (2022) Effects of Multispecies

Probiotic on Intestinal Microbiota and Mucosal Barrier Function of Neonatal Calves Infected With

E. coli K99

Front. Microbiol. 12:813245. doi: 10.3389/fmicb.2021.813245
Altered gut microbiota are implicated in inflammatory neonatal calf diarrhea caused by E. coli K99. Beneficial probiotics are used to modulate gut microbiota. However, factors that mediate host-microbe interactions remain unclear. We evaluated the effects of a combination of multispecies probiotics (MSP) on growth, intestinal epithelial development, intestinal immune function and microbiota of neonatal calves infected with E. coli K99. Twelve newborn calves were randomly assigned as follows: C (control, without MSP); D (E. coli O78:K99 + gentamycin); and P (E. coli O78:K99 + supplemental MSP). All groups were studied for $21 \mathrm{~d}$. MSP supplementation significantly (i) changed fungal Chao1 and Shannon indices of the intestine compared with group D; (ii) reduced the relative abundance of Bacteroides and Actinobacteria, while increasing Bifidobacteria, Ascomycetes, and Saccharomyces, compared with groups C and D; (iii) improved duodenal and jejunal mucosal SIgA and total Short Chain Fatty Acids (SCFA) concentrations compared with group D; (iv) increased relative ZO-1 and occludin mRNA expression in jejunal mucosa compared with group D; and (v) enhanced intestinal energy metabolism and defense mechanisms of calves by reducing HSP90 expression in E. coli $\mathrm{K} 99$, thereby alleviating the inflammatory response and promoting recovery of mucosal function. Our research may provide direct theoretical support for future applications of MSP in ruminant production.

Keywords: multispecies probiotic, immune function, microbiota function, neonatal calves, E. coli K99

\section{INTRODUCTION}

Newborn calf diarrhea (NCD) can cause huge economic losses due to high morbidity and mortality (Walker et al., 1998; Cho and Yoon, 2014; Brunauer et al., 2021). The risk factors associated with diarrhea include the environmental conditions, nutritional levels, and immune status of calves (Klein-Jöbstl et al., 2014; Al Mawly et al., 2015). The most common enteric pathogens include Escherichia coli, Salmonella, Cryptosporidium and Rotavirus (Moon et al., 1978; Gulliksen et al., 2009; da Silva Medeiros et al., 2015). Enterotoxigenic Escherichia coli (ETEC), which constitute the most common cause of neonatal calf diarrhea globally, have been extensively studied over the past 40 years (Bywater and Logan, 1974; González Pasayo et al., 2019). Neonatal calves are most susceptible E. coli K99 ETEC infections during the first 4 days of life (Krogh, 1983; Acres, 1985). 
The E. coli K99 antigen binds to the small intestinal mucosa and gradually decreases from the first $12 \mathrm{~h}$ of adhesion. This adhesion ability is related to age (Runnels et al., 1980). However, in ETEC, this ability increases after the 3rd week of age (Bulgin et al., 1982; Izzo et al., 2011). Antibiotics have been used to treat E. coli that cause diarrhea (Sunderland et al., 2003), where these antibiotics not only affect the target pathogens, but also beneficial microorganisms in the intestine, resulting in longterm changes in intestinal microbiota being associated with the disease. Application of antibiotics also exerts many other side effects, such as intestinal barrier dysfunction and the emergence of carcinogenic and drug-resistant bacteria, which greatly affect the usefulness of antibiotics (Raheem et al., 2021). Probiotics, which are considered as sustainable alternatives to antibiotics, can be used to prevent and treat diarrhea in humans and animals (Collinson et al., 2020; Dahlgren et al., 2021; Hrala et al., 2021). Many previous studies have demonstrated that supplementing calves with probiotics early in life effectively prevents diarrhea (Malmuthuge and Guan, 2017; Wu et al., 2021a). Lactobacillus acidophilus (Lépine et al., 2018), Bacillus subtilis (Sambanthamoorthy et al., 2014; Shen et al., 2017; Memon et al., 2021) and Saccharomyces cerevisiae (Chiaro et al., 2017; Bitla et al., 2021) has the ability to resist pathogen adhesion and enhance the intestinal barrier function (Sanchez et al., 2010; Younis et al., 2017).

In this study, we evaluated whether newborn calves were infected with $E$. coli K99, and whether supplementation with MSP enhanced the integrity of the intestinal barrier and local and systemic immune responses of calves, by regulating intestinal microbiota and ameliorating intestinal dysfunction caused by inflammation. In addition, we investigated the recovery of damaged intestinal function and explored the interaction between the diversity of microbiota and the repair of intestinal mucosa.

\section{MATERIALS AND METHODS}

\section{Preparation of Multispecies Probiotics Complex Preparations}

The MSP (L. acidophilus $3 \times 10^{9} \mathrm{CFU} / 1 \mathrm{~g}$, B. subtilis $3 \times 10^{9}$ $\mathrm{CFU} / 1 \mathrm{~g}$, and $S$. cerevisiae $1 \times 10^{9} \mathrm{CFU} / 1 \mathrm{~g}$ ) was prepared by the Biological Feed Laboratory of the College of Animal Science and Technology, Shihezi University, and the MSP preparation method is described in the previous study (Wu et al., 2021b).

\section{Experimental Design}

Thirty-six male Holstein calves (body weight $40.1 \pm 0.6 \mathrm{~kg}$; age $5 \pm 2$ ) were used for this study. Three groups, each containing 12 calves that were randomly assigned using a random number generator (Microsoft Corp., Redmond, WA), were formed as follows: (i) the control group (C) fed a basal diet and not challenged with E. coli K99; (ii) the diarrhea group (D) also fed a basal diet and orally challenged with E. coli K99 $(30 \mathrm{~mL}$; $1 \times 10^{9} \mathrm{CFU} / \mathrm{mL}$ ) and antibiotic support therapy (intramuscular gentamicin $20 \mathrm{~mL} /$ days, injection lasted for 2 days); and (iii) the MSP group (P): fed MSP every day from the next day $\left(7.0 \times 10^{9} \mathrm{CFU} / \mathrm{g} ; 2 \mathrm{~g} / \mathrm{calf}\right)$ after orally challenged with E. coli $\mathrm{K} 99$ $\left(30 \mathrm{~mL} ; 1.0 \times 10^{9} \mathrm{CFU} / \mathrm{mL}\right)$. This is because the best effect was obtained with $2 \mathrm{~g}$ MSP per day according to a previous study of ours (Wu et al., 2021a), MSP which is in the form of a powder, was administered via milk. The basal diet (Supplementary Table 1) was free of antibiotics. The experimental treatments lasted $21 \mathrm{~d}$, during which all the animals had free access to fresh water and starter concentrate. The starter concentrate, provided by Xinjiang Urumqi Zhengda Feed Co., Ltd. (Urumqi, China) was fed to the calves from day 4. The study was conducted between April and May 2020 at the Shu Rui Farm (Shihezi, China). The calves were maintained according to the standards for the professional guidance process for feeding and management of the Shu Rui farm. The health of the calves was monitored and recorded after birth and throughout the experimental period.

\section{Sample Collection}

Blood samples were obtained from six calves before morning feeding on day 21, $10 \mathrm{~mL}$ of blood being collected from the jugular vein of each calf with an anticoagulant vacuum blood collection tube, during the course of $30 \mathrm{~min}$. The serum was centrifuged at 3,000 rpm for $15 \mathrm{~min}$, separated into a centrifuge tube, and stored in the frozen state at $-20^{\circ} \mathrm{C}$ until needed for testing.

Samples of intestinal tissue, mucosa, and contents (mid duodenum, mid jejunum, mid ileum, mid cecum, mid colon, and rectum) were obtained from different intestinal regions of the same six calves on day 21 of the experiment. Next, the 18 calves ( 6 in each group) were humanely sacrificed by injecting $4 \%$ sodium pentobarbital solution. Intestinal tissues were stored in $4 \%$ paraformaldehyde fixative (Biosharp, China). Samples of the mucosa and intestinal contents were stored in $50 \mathrm{~mL}$ cryotubes, and divided into three $2 \mathrm{~mL}$ sterile, enzyme-free cryotubes, which were immediately placed in liquid nitrogen for rapid freezing and stored at $-80^{\circ} \mathrm{C}$ until needed for further analyses. All experimental steps were aseptically conducted and all intestinal tissues and digests were obtained within $20 \mathrm{~min}$ after euthanasia (Roth et al., 2009).

\section{Bacterial 16S rRNA and Fungal Internal Transcribed Spacer Gene High-Throughput Sequencing}

Total gut microbial genomic DNA was extracted, wherein the primer sequences as well as PCR conditions used for the amplification of bacterial and fungal DNA were in accordance with those described in a previous study of ours (Wu et al., 2021a). According to the standard protocol of Majorbio Bio-Pharm Technology Co., Ltd. (Shanghai, China), paired-end sequencing was performed on the Illumina MiSeq PE300 platform/NovaSeq PE250 platform (Illumina, San Diego, United States). The sequences were submitted to GenBank under accession number SRP329437.

\section{Processing of Sequence Data}

Key steps involved in sequencing data analysis are as follows. First, in order to obtain clean readings by eliminating adapter 
contamination and low quality data, the data was preprocessed to connect overlapping double-ended (COPE) software (V1.2.1) to obtain clean double-ended readings incorporated into labels (Liu et al., 2012). Bacterial tags were classified as operational taxonomic units (OTUs) based on 97\% sequence similarity via Mothur (v1.31.2) softwares (Schloss et al., 2009). Bacterial sequences representative of OTUs was classified using a Mothur software script based on the Ribosomal Database Project (RDP) database (Cole et al., 2009). Fungal tags were clustered into OTUs based on 97\% sequence similarity, using USEARCH (v7.0.1090) software (Edgar, 2013). The RDP classifier (v.2.2), based on the UNITE database, was used to classify fungal OTU representative sequences (Abarenkov et al., 2010). Mothur (v1.31.2) was used to calculate the Chao 1 index, the Shannon index, and the Simpson index, and R (v3.0.3) software was used to draw a sparse curve. QIIME (v1.80) Principal coordinate analysis (PCoA) software was used to plot beta diversity, using weighted UniFrac distance.

\section{Analysis of Small Intestine Immune Function by ELISA}

The double-antigen sandwich method was used to determine immunoglobulin $\mathrm{M}$ (IgM), immunoglobulin A (IgA), immunoglobulin G (IgG), tumor necrosis factor- $\alpha$ (TNF$\alpha$ ), and interleukin- 2 in calf serum (IL-2). Interleukin-1 $\beta$ (IL-1 $\beta$ ), interleukin-4 (IL-4), and secretory immunoglobulin (SIgA) of small intestine contents were determined using a biochemical kit. ELISA kits and biochemical kits were purchased from Shanghai Enzyme Link Biotechnology Co., Ltd. All tests were performed according to the manufacturer's instructions.

\section{Real-Time Quantitative PCR}

Tissue preparation for mRNA quantification was recently described by Schäff et al. (2018). The optical density measured at 260:280 using a spectrophotometer (NanoPhotometer, Implen $\mathrm{GmbH}$, Munich, Germany) was used to estimate the quantity and quality of total RNA. For cDNA synthesis, 750 ng RNA used $200 \mathrm{U}$ reverse transcriptase MMLV-RT RNase (H-) point mutant (Promega, Madison, WI) and $250 \mathrm{pmol}$ random hexamer primers (Metabion International AG, Planegg-Steinkirchen, Germany) Dilute the cDNA 1:4 with diethyl pyrocarbonate water and store aliquots at $-80^{\circ} \mathrm{C}$. Specific primers were

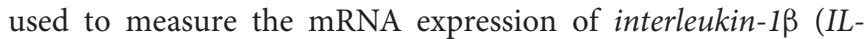
$1 \beta$ ), interleukin-2 (IL-2), tumor necrosis factor alpha (TNF$\alpha)$, Toll-like receptors (TLRs), nuclear factor kappa-B (NF$\kappa B)$, zona occludens-1 (ZO-1), occludin, claudin, and the copy number of $16 \mathrm{~S}$ rRNA genes of total bacteria, L. acidophilus, B. subtilis, S. cerevisiae, and E. coli $\mathrm{K} 99$ in the small intestinal mucosa (duodenum, jejunum and ileum). Primers were designed using Primer 3 version 0.4.0 (Untergasser et al., 2012) or via literature surveys as shown (Supplementary Table 2). $\beta$-actin was used as a reference gene to normalize data. Data are presented as the ratio between the copy numbers of relevant genes and the abundance of reference genes. Relative expression of the target genes was determined using the 2- $\triangle \triangle$ Ct method.

\section{Short Chain Fatty Acids Concentration}

A sample (100 mg) of jejunum contents was weighed, transferred to a $5 \mathrm{~mL}$ tube (containing 25\% phosphoric acid), and vortexed vigorously until completely dissolved (4:1; v:v). As described in $\mathrm{Bi}$ et al. (2021), the concentration of acetate, propionate, butyrate, isobutyrate, isovalerate, and valerate was measured by gas chromatography. The concentration of Short Chain Fatty Acids (SCFA) in the jejunum is expressed as $\mu \mathrm{g} / \mathrm{g}$.

\section{Analysis of the Metaproteome in Jejunum Contents}

Fecal contents in the jejunum samples were enriched with microbial cells via differential centrifugation, according to the method reported by Tanca et al. (2017). The bicinchoninic acid (Beyotime, Shanghai) method was used to quantitatively extract the protein in the jejunum sample, and SDS polyacrylamide gel electrophoresis was used to evaluate the quality of the protein extract in the sample. The protein sample $(100 \mu \mathrm{g})$ was digested by the FASP method (Wiśniewski et al., 2009). After enzymolysis, similar amounts from each biological sample were removed and mixed. Of this, $100 \mu \mathrm{g}$ were classified via high $\mathrm{pH}$ RP reversedphase chromatography (chromatograph: Agilent 1100 (including Chemstation, $214 \mathrm{~nm}$ dad detector, and vacuum degasser).

The column was Waters XBridge C18 $(5 \mu \mathrm{m}, 4.6 \times 250 \mathrm{~mm}$, 120 Å). Protein Discoverer 2.1.0182 (Thermo Fisher Scientific, Rockford, IL, United States) was used for protein retrieval and analysis. Biological samples were collected for dataindependent acquisition (DIA) and analyzed quantitatively using Skyline software (Department of Genome Sciences, University of Washington, Seattle, WA) (Egertson et al., 2015).

The sequences were submitted to MassIVE and can be downloaded via the following address: $\mathrm{fttp}: / /$ massive.ucsd.edu/MSV000087975/.

\section{Liquid Chromatography-MS/MS Analysis}

Jejunum content samples were analyzed using an online nanospray Orbitrap Fusion Lumos Tribrid mass spectrometer (Thermo Fisher Scientific, MA, United States) with an EASYnLC system (Thermo Fisher Scientific, MA, United States). The peptides were dissolved in solvent A $(0.1 \%$ formic acid in water $)$ spiked with $1 \times$ iRT standard (iRT Kit; Biognosys, Schlieren, Switzerland). Exactly $1 \mu \mathrm{g}$ of peptide sample was loaded onto an Acclaim PepMap C18 column $(75 \mu \mathrm{m} \times 25 \mathrm{~cm})$ and separated using 120-min linear gradient. Column flow rate was maintained at $400 \mathrm{~nL} / \mathrm{min}$, while column temperature was maintained at $40^{\circ} \mathrm{C}$. An electrospray voltage of $2100 \mathrm{~V}$ was applied. A full scan was performed at $\mathrm{m} / \mathrm{z} 350-1,200$ with a resolution of 120,000 at $\mathrm{m} / \mathrm{z}=200$, and maximum injection time of $50 \mathrm{~ms}$. The MS/MS scan was performed with higher-energy collisionactivated dissociation for $\mathrm{m} / \mathrm{z}$ 200-2,000 with a resolution of 30,000 at $\mathrm{m} / \mathrm{z}=200$, and maximum injection time of $90 \mathrm{~ms}$. Collision energy was $32 \%$, and the stepped collision energy was $5 \%$. DIA was performed with 25 variable isolation windows with a $1 \mathrm{Da}$ overlap and total cycle time of $3 \mathrm{~s}$.

The DDA mode was used to construct a spectral library for protein identification and quantification using DIA. One 
microgram of peptides from each sample was combined, and the mixture was redissolved in $50 \mu \mathrm{L}$ of buffer $\mathrm{C}$ ( $20 \mathrm{mM}$ ammonium formate in water, $\mathrm{pH}=10.0$, adjusted by ammonium hydroxide). Next, the combined peptide solution was subjected to high$\mathrm{pH}$ reversed-phase Liquid Chromatography (LC) fractionation via an Ultimate 3000 system (Thermo Fisher Scientific, MA, United States) with a C18 column $(4.6 \mathrm{~mm} \times 250 \mathrm{~mm}$, $5 \mu \mathrm{m})$. Column flow rate was maintained at $1 \mathrm{~mL} / \mathrm{min}$, while column temperature was maintained at $40^{\circ} \mathrm{C}$. The fractions were continuously collected. Each fraction was dried in a vacuumfreeze dryer, redissolved in $50 \mu \mathrm{L}$ of solvent A $(0.1 \%$ formic acid in water), and subjected to LC-MS/MS analysis; the injection volume was $5 \mu \mathrm{L}$. Dynamic exclusion was enabled within a duration of $30 \mathrm{~s}$. An MS/MS scan was performed with 1.6 Da isolation window widths. The other MS parameters, LC gradient conditions, and LC column were similar to those used in the DIA experiments.

\section{Microbial Function Analysis}

All quantifiable microbial protein sequences were annotated using the Clusters of Orthologous Genes (COG) database (version 2014), as previously described (Zhang et al., 2016). KEGG ortholog (KO) annotation of protein sequences was conducted using the GhostKOALA web application (Kanehisa et al., 2016). Taxonomic assignment of the proteins was performed using MEGAN 6 (Huson et al., 2007). The taxonomy of a protein group was assigned using the lowest common ancestor (LCA) of all proteins within that protein group.

Pathway enrichment analysis was performed using STRING (version 10.5) (Szklarczyk et al., 2017). Protein interaction networks were exported from STRING and visualized using Cytoscape software (version 3.4.0).

\section{Statistical Analysis}

The Durbin Watson test was used to examine the randomness of initial weight data and the effectiveness of randomization. The GLIMMIX program SAS 9.4 was used to analyze serum immunoglobulin, SCFA concentration, SIgA and fecal microbial data on the basis of repeated measurement and compound symmetrical variance and covariance structure. The fixed effect of treatment, day, the interaction between treatment and day, and the random effect of calf identity were included in the repeated measurement model. A melting curve analysis was generated to verify the specificity of the reaction after each quantitative real-time PCR analysis. Select housekeeping gene $\beta$-Actin was used as a reference gene to normalize the mRNA expression of the target gene. The gene expression data of replicated samples were calculated using the CT method (Pfaffl, 2001). The relative expression of target genes in group $\mathrm{C}$ was set to 1.0. Each sample was measured in triplicate. The data are expressed as the least squares mean and the standard error of the mean. Tukey's multi range test was used to evaluate the differences between the treatment groups.

DDA data were analyzed using Proteome Discoverer 2.1.0182 (Thermo Fisher Scientific, Rockford, IL, United States). MS1 tolerance was set to $10 \mathrm{ppm}$, and MS/MS tolerance was 0.02 Da. All DDA MS/MS spectra were searched against the database of bacterial proteomes downloaded from the UniProt database $\left(23,730,617\right.$ protein entries, ${ }^{1}$ access date July 2019). The Bacteria, Eukaryota, and Archaea databases in the Uniprot database were "searched and compared." The FDR cut-off for PSM, peptide, and protein group levels was $1 \%$. Raw DIA data were then processed and analyzed via Skyline (Department of Genome Sciences, University of Washington, Seattle, WA, United States) using the default settings. The top three filtered peptides that passed the $1 \% Q$-value cut-off were used to calculate the major group quantities.

Annotation of identified proteins was performed using KOBAS $^{2}$ in which several databases (i.e., GO, KEGG, and eggNOG) were integrated. Differentially expressed proteins were analyzed using mapDIA, a software package used to preprocess and statistically analyze quantitative proteomics data. The abundance of each phylum was calculated by summing the intensities of all proteins corresponding to that phylum. Data visualization was conducted using $\mathrm{R}$ packages, including heatmaps, circles, and ggplot2.

\section{RESULTS}

\section{Gut Microbial Diversity}

Our data indicated that bacterial amplicon sequencing of the intestinal content microbiota generated 6,978,315 high-quality sequences that were assigned to a total of 33952 OTUs based on a $97 \%$ nucleotide sequence similarity, with an average of 32,112 sequences per sample (21,230-35,090 sequences). PCoA (Supplementary Figure 2) and analysis of similarities (ANOSIM) analyses (Supplementary Table 3) revealed that supplementing E. coli infected neonatal calves with MSP induced significant differences in the microbial structure of different gut region digesta-attached microbiota. The diversity of microbiota in the $\mathrm{D}$ and $\mathrm{P}$ groups was similar to that of control (C) on day 21, whereas the duodenal, ileal and jejunal microbiota of the D and $\mathrm{P}$ groups demonstrated a marked shift along principal component 1 compared with that of the $\mathrm{C}$ group.

Bacterial diversity on day 21, which was estimated using Chaol, Shannon, and Simpson indices, was lowest in the jejunum, ileum, cecum, and colon of the D group, as compared to those of the $\mathrm{H}$ and $\mathrm{P}$ groups. In addition, the Chaol and Shannon indices for the $\mathrm{C}$ group and $\mathrm{P}$ group were all significantly higher than those for the D group. There were no significant differences between the diversities in the duodenums of the $\mathrm{C}$ and $\mathrm{D}$ groups (Figure 1 and; Supplementary Table 4).

The fungal diversity index, Chao 1, for the cecum, colon, and rectum of the $\mathrm{D}$ group was significantly lower than that for the $\mathrm{C}$ and $\mathrm{P}$ groups $(P<0.01 ; P=0.02$; and $P<0.01$, respectively). The Shannon diversity index for the jejunum, ileum, cecum, and rectum of the $\mathrm{D}$ group was significantly lower than that of the $\mathrm{C}$ and $\mathrm{P}$ groups $(P<0.01 ; P=0.01 ; P<0.01$; and $P<0.01$, respectively). There were no significant differences between the $\mathrm{C}$ and $\mathrm{P}$ groups. The Simpson index of fungal diversity for the

\footnotetext{
${ }^{1}$ https://www.uniprot.org/

${ }^{2}$ http://kobas.cbi.pku.edu.cn/
} 

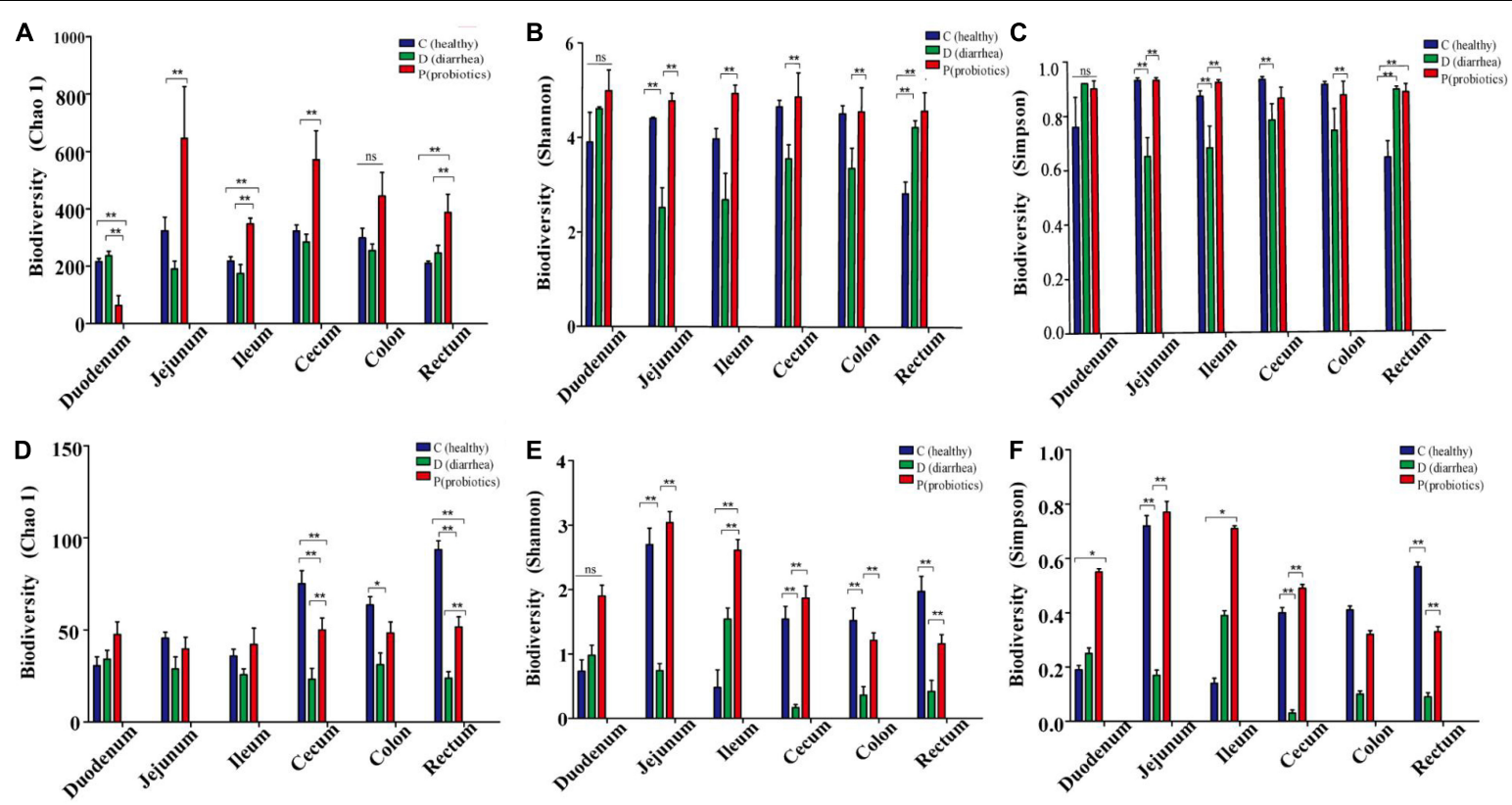

FIGURE 1 | The abundance and diversity index of microorganisms in different intestinal contents of Holstein calves. (A-F) Represent the abundance of Chao1, Shannon and Simpson and the diversity of bacterial and fungal microflora diversity indexes. ${ }^{\star} P<0.05,{ }^{\star \star} P<0.01$.

jejunum, cecum, and rectum of group $\mathrm{D}$ was significantly lower than that of the $\mathrm{C}$ and $\mathrm{P}$ groups $(P<0.01 ; P<0.01$; and $P<0.01$, respectively) (Figure 1 and Supplementary Table 4). In addition, the results indicated that treatment and gut segment had a significant effect on the $\alpha$-diversity of bacteria and fungi.

\section{Relative Abundance of Bacterial and Fungal Taxa}

Firmicutes, Actinobacteria, and Bacteroidetes were the dominant bacterial phyla in the duodenum, jejunum, ileum, cecum, colon, and rectum, followed by Proteobacteria and Fusobacteria. The relative abundance of Firmicutes in the duodenum $(P=0.01)$ and jejunum $(P=0.04)$ of neonatal calves in the $\mathrm{D}$ group was higher than those in the $\mathrm{C}$ and $\mathrm{P}$ groups. The relative abundance of Actinobacteria in the duodenum $(P=0.01)$ and jejunum $(P=0.03)$ of calves in the $\mathrm{D}$ group was lower than that in the $\mathrm{C}$ and $\mathrm{P}$ groups, whereas in the ileum $(P=0.01)$ it was higher than that in the $\mathrm{C}$ and $\mathrm{P}$ groups. The relative abundance of Bacteroidetes in the jejunum $(P=0.03)$ of calves in the $D$ group was lower than that in the $\mathrm{C}$ and $\mathrm{P}$ groups, while no significant differences were observed between other intestinal segments (Figure 2 and Supplementary Table 5).

The top 20 genera at the genus level, were detected and further analyzed: Olsenella, Prevotella_7, Selenomonas, Bifidobacterium, Lactobacillus, Blautia, Faecalibacterium, Syntrophococcus, and Ruminococcaceae_UCG-005 were the predominant bacterial genera in the duodenum and jejunum. The relative abundances of Sarcina $(P<0.01)$, Streptococcus $(P<0.01)$, Selenomonas $(P<0.01)$, and Lactobacillus $(P<0.01)$ in the duodenums of the $\mathrm{D}$ group were significantly higher than those of the $\mathrm{C}$ and $\mathrm{P}$ groups.
However, the relative abundance of Bifidobacterium in the duodenum $(P=0.02)$, jejunum $(P=0.02)$, and ileum $(P=0.01)$ of the $\mathrm{P}$ group was significantly higher than that of the $\mathrm{C}$ and $\mathrm{D}$ groups. The relative abundance of Sharpea in the jejunum $(P=0.04)$ of the $\mathrm{D}$ group was significantly lower than that of the $\mathrm{C}$ and $\mathrm{P}$ groups $(P=0.02)$, while the relative abundance of Prevotella_7 in the jejunum of the $\mathrm{P}$ group was significantly higher than that of the $\mathrm{C}$ and $\mathrm{D}$ groups. No significant differences were observed between other gut regions. In addition, no significant difference was observed between the hindguts of the three groups (Figure 2 and Supplementary Table 6).

The microbial composition of the calf gut indicated that Ascomycota was the dominant phylum followed by Basidiomycota and Mucoromycota (Figure 2 and Supplementary Table 6). A trend toward greater relative abundance of Ascomycota was observed in MSP supplemented neonatal calves compared to that in the $\mathrm{C}$ and $\mathrm{D}$ groups $(P<0.10)$. However, the relative abundance of Mucoromycota in the colon of group $\mathrm{D}$ neonatal calves was higher than that in the group $\mathrm{C}$ and $\mathrm{P}$ neonatal calves $(P=0.03)$. In addition, the relative abundance of Basidiomycota in the $\mathrm{C}$ group was significantly higher than that in the other two groups $(P=0.01)$.

Calf gut microbial composition indicated that Saccharomyces, Aspergillus, Wardomyces, and Acaulium were the predominant genera, followed by Cladosporium, Filobasidium, Geotrichum, Mortierella, Kazachstania, Kernia, Cutaneotrichosporon, and Scopulariopsis (Figure 2 and Supplementary Table 6). The relative abundances of Acaulium in the duodenum, jejunum, ileum, and cecum of the $\mathrm{D}$ group tended to be higher than those of the $\mathrm{C}$ and $\mathrm{P}$ groups $(\mathrm{P}=0.01 ; \mathrm{P}<0.01 ; \mathrm{P}<0.01$; and $\mathrm{P}=0.01$, respectively). The relative abundance of Saccharomyces in the 

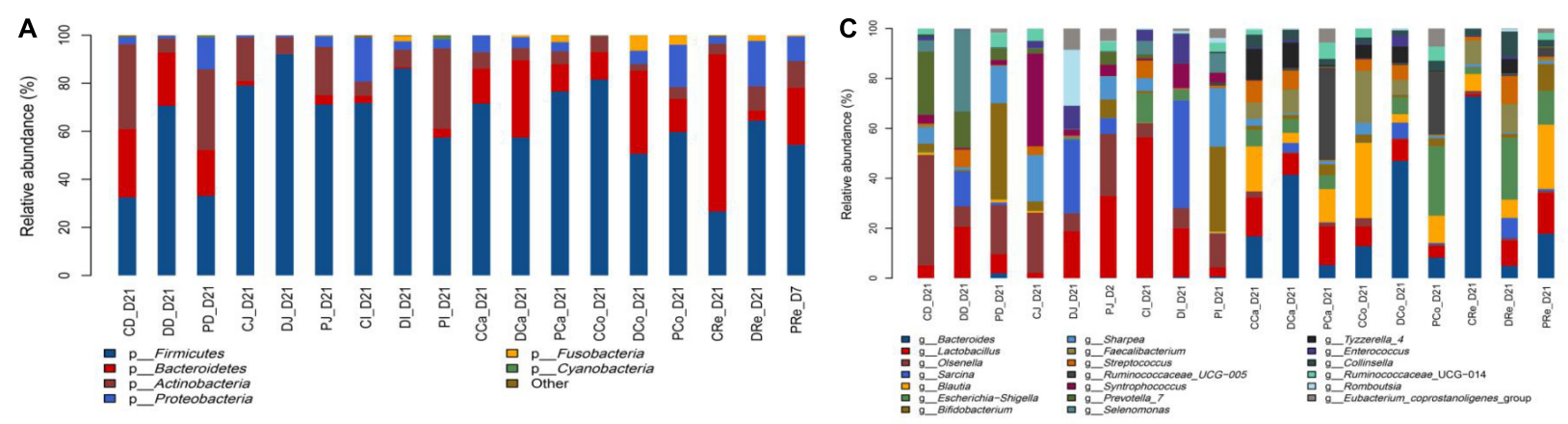

B

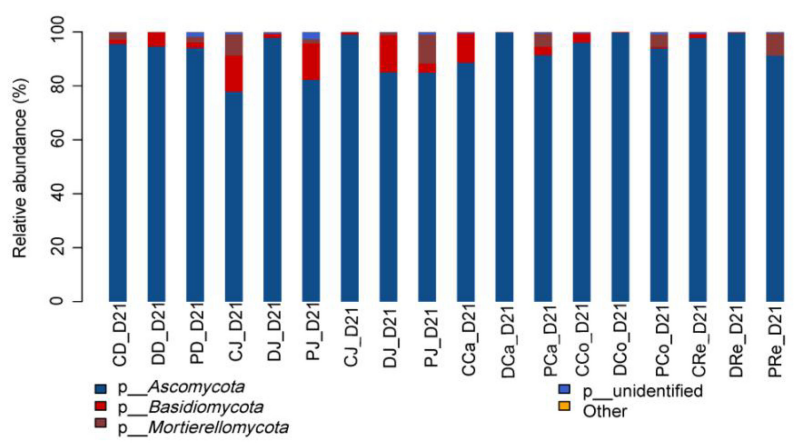

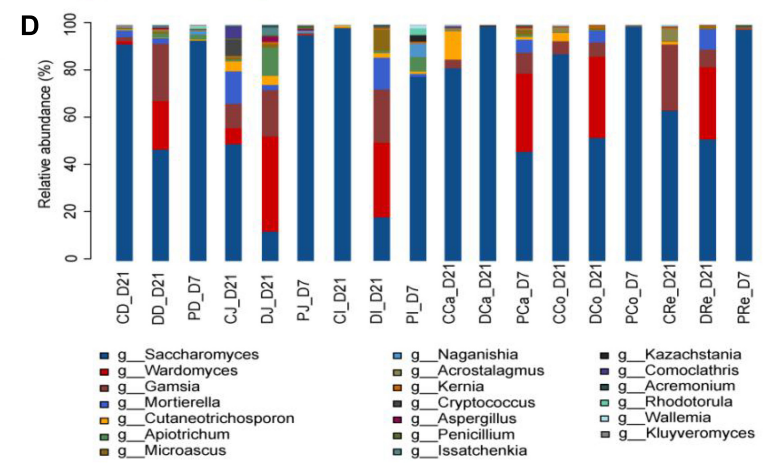

FIGURE 2 | Composition of the different gut region digesta-associated microbial community. (A,C) Show the composition of the microbial community in the three groups $(C, D$, and $P)$ with respect to bacterial phyla and genera. (B,D) Show the composition of the microbial community in the three groups $(C$, $D$, and $P)$ with respect to fungal phyla and genera $(C D, D D$, and PD represent groups $C, D, P$ dudenum; CJ, DJ, and PJ, represent groups C, D, P jejunum; CI, DI, and PI represent groups C, D, P ileum; CCa, DCa, and PCa, represent groups C, D, P cecum; CCo, DCo, and PCo, represent groups C, D, P colon; CRe, Dre and PRe, represent groups C, D, P rectum).

duodenum, jejunum, and ileum of the $\mathrm{P}$ group was significantly higher than that of the $\mathrm{C}$ and $\mathrm{D}$ groups $(\mathrm{P}<0.01 ; \mathrm{P}<0.01$; and $\mathrm{P}=0.03$, respectively). The relative abundance of Wardomyces in the jejunum, ileum, cecum, colon, and rectum of group D was significantly higher than that of the $\mathrm{C}$ and $\mathrm{P}$ groups $(\mathrm{P}<0.01$; $\mathrm{P}=0.02 ; \mathrm{P}=0.03 ; \mathrm{P}=0.02 ;$ and $\mathrm{P}=0.02$, respectively). The relative abundances of Kazachstania and Acremonium in group $\mathrm{P}$ were significantly higher than those in the $\mathrm{C}$ and $\mathrm{D}$ groups $(\mathrm{P}<0.01)$. The relative abundance of Cladosporium and Pichia in the jejunum of group $\mathrm{D}$ was significantly higher than that of the $\mathrm{C}$ and $\mathrm{P}$ groups $(\mathrm{P}<0.01)$. In addition, the relative abundance of fungi at the phylum and genus levels was significantly different in the different treatment groups of neonatal calves infected with E. coli K99.

\section{Immune Function}

MSP supplementation caused significant differences in the levels of IgM and TNF- $\alpha$ in the sera of neonatal calves infected with E. coli $\mathrm{K} 99(P<0.05)$, wherein the $\mathrm{C}$ group differed significantly from the P group $(P<0.01)$, while the calf sera of the $\mathrm{C}, \mathrm{D}$, and $\mathrm{P}$ groups showed significant differences. The concentrations of IgG, IgA, IL-1, IL-2, and IL-4 were not significantly affected $(P>0.05)($ Table 1$)$.

The effect of MSP supplementation on SIgA in the duodenum, jejunum, and ileum mucosa of neonatal calves infected with E. coli K99 was significantly different from that of the D and
$\mathrm{P}$ groups $(P<0.01)$. In addition, SIgA concentrations in the duodenum, jejunum, and ileum mucosa of calves in group $P$ were significantly higher than those in group $\mathrm{D}(P<0.01)$. The SIgA concentrations in the duodenum and jejunum mucosa of calves

TABLE 1 | Effect of MSP supplementation on the serum immune function and the content of SlgA in neonatal calves intestinal mucosa of neonatal calves infected by E. coli K99.

\begin{tabular}{llllll}
\hline Item & \multicolumn{3}{c}{ Treatment $^{1}$} & & P-value \\
\cline { 2 - 4 } & C & D & P & SEM & \\
\hline $\operatorname{lgM}(\mu \mathrm{g} / \mathrm{mL})$ & $2780.1^{\mathrm{a}}$ & $2058.21^{\mathrm{b}}$ & $2234.47^{\mathrm{b}}$ & 113.40 & 0.01 \\
$\operatorname{lgG}(\mathrm{mg} / \mathrm{mL})$ & 5.84 & 6.23 & 6.68 & 0.25 & 0.44 \\
$\operatorname{lgA}(\mu \mathrm{g} / \mathrm{mL})$ & 1533.56 & 1388.96 & 1318.10 & 43.41 & 0.11 \\
IL-1 $(\mathrm{pg} / \mathrm{mL})$ & 376.11 & 354.41 & 331.84 & 9.94 & 0.19 \\
IL-2 $(\mathrm{pg} / \mathrm{mL})$ & 430.22 & 440.38 & 420.70 & 11.86 & 0.81 \\
IL-4 $(\mathrm{pg} / \mathrm{mL})$ & 38.91 & 39.98 & 40.92 & 0.66 & 0.49 \\
TNF- $\alpha(\mathrm{pg} / \mathrm{mL})$ & $133.55^{\mathrm{a}}$ & 130.81 & 116.58 & 3.07 & 0.04 \\
SlgA $(\mu \mathrm{g} / \mathrm{g})$ & & & & & \\
Duodenum & $447.78^{\mathrm{a}}$ & $297^{\mathrm{C}}$ & $360.16^{\mathrm{b}}$ & 18.25 & $<0.01$ \\
Jejunum & $431.76^{\mathrm{a}}$ & $281.84^{\mathrm{c}}$ & $368.32^{\mathrm{a}}$ & 18.49 & $<0.01$ \\
Ileum & $419.61^{\mathrm{a}}$ & $278.17^{\mathrm{b}}$ & $364.68^{\mathrm{a}}$ & 19.56 & $<0.01$ \\
\hline
\end{tabular}

$a, b$ Means in the same row with different superscripts are significantly different $(P \leq 0.05)$.

${ }^{1} \mathrm{C}$, Control group; D, Diarrhea group; P, MSP group; respectively. 


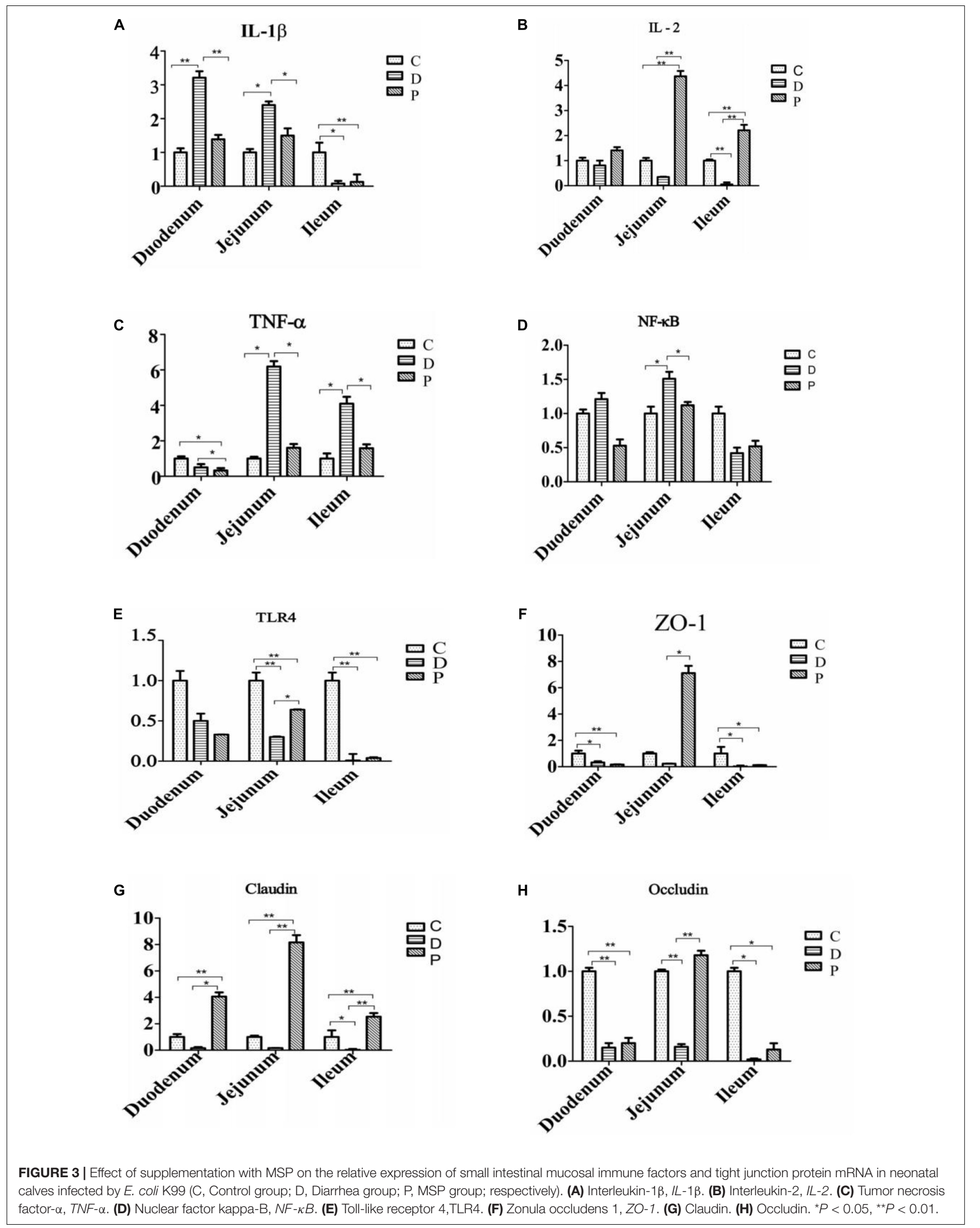


in the $\mathrm{C}$ group were significantly higher than those in the $\mathrm{D}$ and P groups $(P<0.01)$ (Table $\mathbf{1})$.

\section{Expression of Inflammation-Related and Intestinal Barrier-Related Genes}

The relative expression of $I L-1 \beta, N F-\kappa B$, and TNF- $\alpha$ mRNA in the duodenal and jejunal mucosa of the $\mathrm{D}$ group was significantly higher than those of the $\mathrm{C}$ and $\mathrm{P}$ groups $(\mathrm{P}<0.01)$. The relative expression of $I L-2 \mathrm{mRNA}$ in the jejunum of calves in the P group was significantly higher than that in the $\mathrm{D}$ group $(P<0.01)$. The relative expression of ZO-1 mRNA in the jejunum mucosa of calves in group $\mathrm{P}$ was significantly higher than that in groups $\mathrm{C}$ and $\mathrm{D}(P<0.01)$. The relative expression of claudin $\mathrm{mRNA}$ in the mucosa of calves in the duodenum, jejunum, and ileum of the $\mathrm{P}$ group was significantly higher. The expression of occludin mRNA was significantly higher in the $\mathrm{P}$ group than in the $\mathrm{C}$ and $\mathrm{D}$ groups $(P<0.01)$, while the relative expression of occludin mRNA in the jejunum and ileum mucosa of calves in group $P$ was significantly lower than that in groups $\mathrm{C}$ and $\mathrm{D}(P<0.01)$ (Figure 3 ).

\section{Short Chain Fatty Acid Concentration in the Jejunum of Neonatal Calves}

To further analyze microbial activity in jejunum contents, we measured the concentrations of short-chain fatty acids (SCFAs), using them as a proxy reflecting microbial metabolic activity in our gut samples. The concentrations of acetate, propionate, butyrate, and isovaleric acid were significantly higher than those in the $\mathrm{C}$ and $\mathrm{P}$ groups (Table 2). The concentration of total SCFA in the $\mathrm{P}$ group was increased compared to that in the $\mathrm{D}$ group, while being significantly higher in the $\mathrm{C}$ group than that in the D group (Table 2). In addition, there were significant differences between the concentrations of acetic acid, propionic acid, butyric, isobutyric, isovaleric, and isocaproic acid contents among the three groups.

\section{Metaproteomics Profiling of Jejunum Content}

An advantage associated with metaproteomics is that the microbial population as well as host proteins can be measured in a single analysis. Therefore, we further analyzed microbial function in the calf jejunum, via a metaproteomics analysis aimed at detecting microbial and host proteins in our samples.

We quantified 22,080 unique peptides and 4,414 proteomes in nine samples, with an average recognition rate of $39 \pm 8 \%$ (mean \pm standard deviation). On average, 2,453 \pm 89 unique peptides and $735 \pm 33$ proteomes were identified for each sample. Among the 4,414 proteomes, 3,679 proteins (83\%) were from host calves, and only 735 (17\%) were from calf jejunumcontent microorganisms. However, host proteins accounted for 5.54 times the intensity of the total proteins. We used macroproteomics to characterize the microbiomes of 9 jejunum samples from groups $\mathrm{C}, \mathrm{D}$, and $\mathrm{P}$ (three samples in each group). The results indicated that 226 showed expressions specific for each group.

Data obtained via further analyses of the gut microbiome function in the jejunum indicated that probiotics caused shifts in intestinal microbiome function, as evidenced by the scatterplot generated from the principal component analysis (PCA) and the Cluster Dendrogram (Figure 4). PCA was performed using calfderived proteins or non-calf proteins (i.e., microbiota-derived) quantified in $\geq 50 \%$ of the samples. The PCA score plot for calf proteins showed an obvious separation among the three groups (Figure 4A). Furthermore, PCA analysis of microbiotaderived proteins also showed obvious separation among the three groups (Figure 4C).

Multivariate analysis of variance (MANOVA) of calfderived proteins yielded greater differences, revealing significant differences $(P<0.01)$ between groups $C$ and D (Figure $4 \mathbf{B}$ ). By contrast, MANOVA of microbiota-derived proteins revealed significant differences between C, D, and P groups (Figure 4D). To identify treatment-related alterations in host and microbiota, we combined samples from $\mathrm{C}, \mathrm{D}$, and $\mathrm{P}$ in jejunal function recovery for further analysis.

\section{Elevated Microbial Response to Carbohydrates and Defense Mechanisms in Neonatal Calves}

To assess microbial function, we annotated all quantified microbial proteins using the COG database and obtained 330 COGs from 24 COG categories. A total of 154 COGs were identified in all three groups (Figures 5, 6).

At the COG category level, we found that category $\mathrm{G}$ (carbohydrate transport and metabolism), category O (posttranslational modification, protein turnover, chaperones) category $\mathrm{V}$ (defense mechanisms), and category $\mathrm{S}$ (function unknown) were significantly increased in the MSP group compared to those of the $\mathrm{C}$ and $\mathrm{D}$ groups (Figure 7). Defense mechanisms in the $\mathrm{P}$ group, in particular, were significantly increased compared to those in the $\mathrm{C}$ and $\mathrm{D}$ groups. Two COGs belonging to defense mechanisms were identified as differentially abundant in the $\mathrm{P}$ group microbiome compared to that in the $\mathrm{C}$ and $\mathrm{D}$ groups (Figure 7). KO annotation identified $516 \mathrm{KOs}$ corresponding to 735 proteins. The Wilcoxon rank-sum test

TABLE 2 | Short chain fatty acid (SCFA) concentration and molar proportion in the jejunum contents of neonatal calves.

\begin{tabular}{lcccccc}
\hline & \multicolumn{3}{c}{ Treatment $^{\mathbf{1}}$} & & P-value \\
\cline { 2 - 4 } SCFA $(\boldsymbol{\mu} \mathbf{g} / \mathbf{g})$ & $\mathbf{C}$ & $\mathbf{D}$ & $\mathbf{P}$ & MSE & \\
\hline Acetic acid & $312.69^{\mathrm{b}}$ & $436.56^{\mathrm{b}}$ & $641.57^{\mathrm{a}}$ & 42.57 & $<0.01$ \\
Propanoic acid & $36.91^{\mathrm{b}}$ & $60.92^{\mathrm{b}}$ & $153.36^{\mathrm{a}}$ & 19.37 & 0.02 \\
Butanoic acid & $736.88^{\mathrm{a}}$ & $58.73^{\mathrm{b}}$ & $182.97^{\mathrm{b}}$ & 12.4 & 0.03 \\
Isobutyric acid & 3.88 & 3.89 & 7.29 & 0.98 & 0.24 \\
Valeric acid & 20.59 & 20.80 & 79.69 & 8.72 & 0.06 \\
Isovaleric acid & $1.76^{\mathrm{b}}$ & $3.86^{\mathrm{b}}$ & $47.98^{\mathrm{a}}$ & 5.5 & 0.02 \\
Hexanoic acid & $1798.44^{\mathrm{a}}$ & $142.91^{\mathrm{b}}$ & $275.89^{\mathrm{b}}$ & 267.41 & 0.01 \\
Isohexanoic acid & $1.76^{\mathrm{a}}$ & $0.00^{\mathrm{b}}$ & $0.00^{\mathrm{b}}$ & 0.31 & 0.02 \\
Total acid & $2312.91^{\mathrm{a}}$ & $972.59^{\mathrm{b}}$ & $1595.47^{\mathrm{ab}}$ & 81.05 & 0.04 \\
\hline
\end{tabular}

$a, b$ Means in the same row with different superscripts are significantly different $(P \leq 0.05)$.

${ }^{1} \mathrm{C}$, Control group; $D$, Diarrhea group; $P, M S P$ group; respectively. 
A

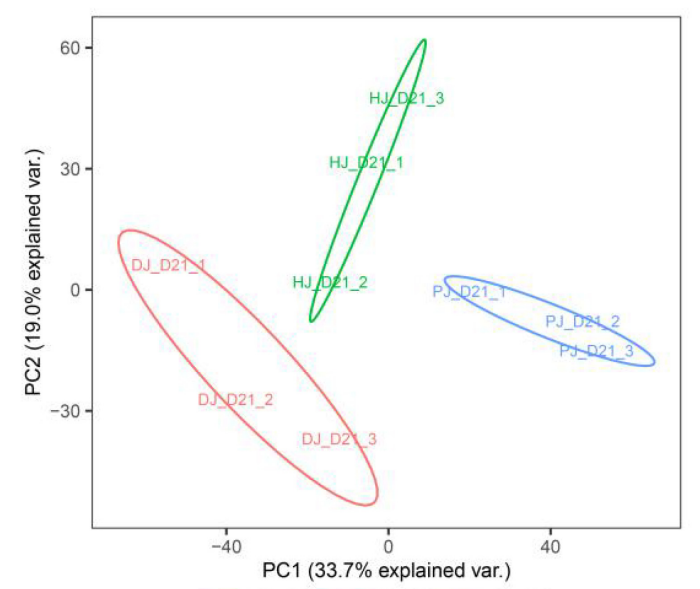

C

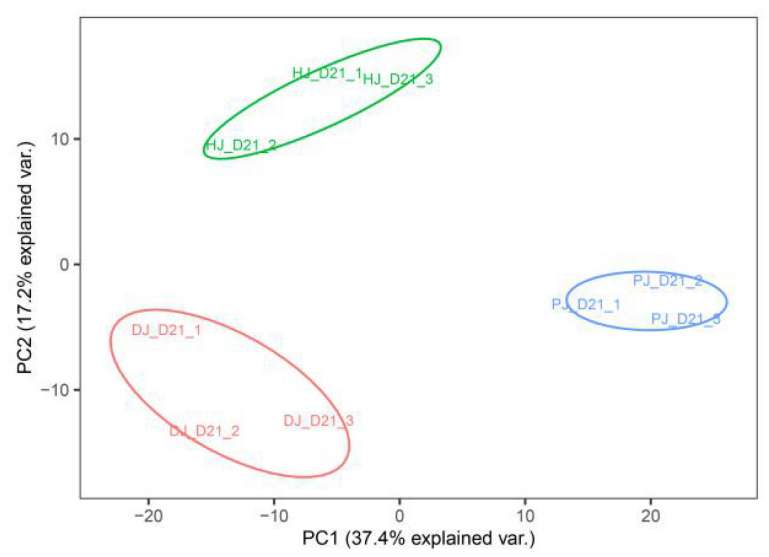

B

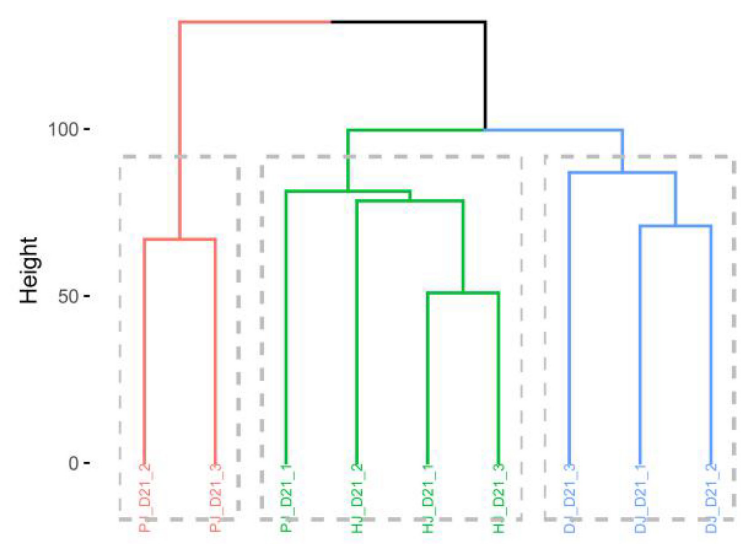

D

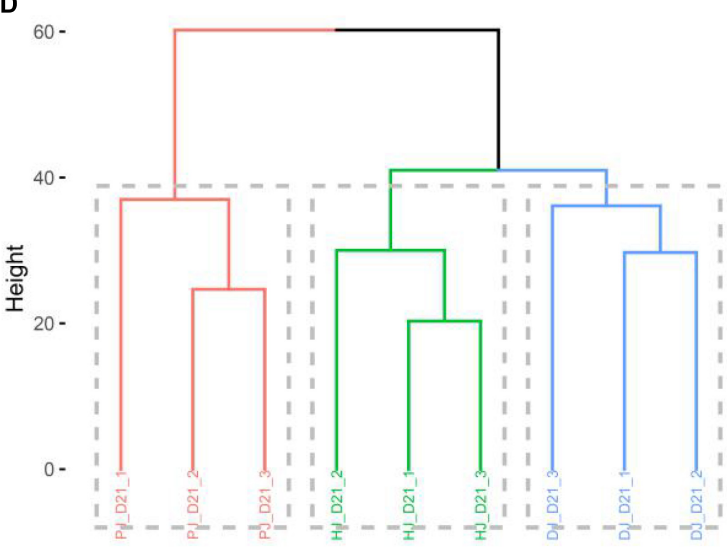

FIGURE 4 | Host and microbiota proteome landscape alterations in neonatal calves infected by E. coli K99. (A,C) PCA score plot of calf-derived and microbiome-derived proteins quantified in $\geq 50 \%$ of the samples; (B,D) group mean clustering based on Mahalanobis distances calculated with MANOVA test using the first 10 PCs of PCA on calf-derives proteins, respectively.

identified 116 proteins that were significantly different among the three groups, among which six were upregulated in the D group and downregulated in the $\mathrm{C}$ and $\mathrm{P}$ groups, where ATPbinding cassette (ABC) transporters (KO:K09810), ubiquitin carboxyl-terminal hydrolases (UCHs)(KO:K05610), Glucose-6phosphate isomerase (KO:K01810), 30S ribosomal protein S9 (A0A099S8L6), and heat shock protein 90 OS (KO:K04079) were significantly upregulated in group D compared with groups C and $\mathrm{P}$ (Figure 6B). Interestingly, dietary supplementation with MSP only decreased the expression of both HSPs, where the difference was significant in the case of HSP90.

We identified 666 microbial species $(666 \pm 27$ species per sample) with a minimum of one distinctive peptide from three different kingdoms (bacteria, fungi, and archaea). Linear discriminant analysis effect size (LEfSe) identified seven phyla and 71 species as differentially abundant among the three groups. All seven differentially abundant phyla, namely Proteobacteria, Firmicutes, Chytridiomycota, Ascomycota, and Basidiomycota, were decreased in group $\mathrm{P}$, compared to those in $\mathrm{D}$, while Blastocladiomycota, Zoopagomycota, and Crenarchaeota, were increased compared to the $\mathrm{D}$ and $\mathrm{C}$ groups. Of the four most significantly changed strains in the D group, Prevotella and Streptomyces, were decreased and Pichia and Selenomonas were increased, respectively, compared to $\mathrm{C}$ and $\mathrm{P}$ groups. This finding agreed with those of a $16 \mathrm{~S}$ rRNA and ITS sequencing study using a similar type of calves. However, in contrast to the 16s rRNA and internal transcribed spacer (ITS) sequencing study using a similar type of calves, Batrachochytrium in the D group was higher than that in the $\mathrm{C}$ and $\mathrm{P}$ groups. Previous studies have indicated that genera identified via metagenomics may differ from those identified via the $16 \mathrm{~S}$ rRNA and ITS sequencing (Walker and Lue, 2015; Hubert et al., 2017; Hu et al., 2018).

\section{Host-Protein in Jejunum of Neonatal Calves}

To identify calf proteins that were differentially abundant in group $\mathrm{D}$ compared to groups $\mathrm{C}$ or $\mathrm{P}$, or in groups $\mathrm{D}$ or $\mathrm{P}$ compared to $\mathrm{C}$, a Venn diagram was conducted for each pair 
[C] Energy_production_and_conversion

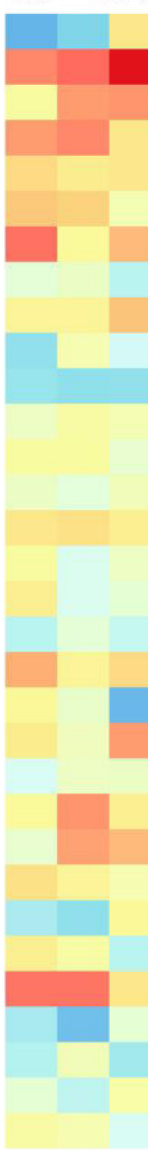

COG0050 Elongation factor Tu

COG0055 ATP synthase subunit beta

COG0056 ATP synthase subunit alpha

COG0074 Succinate--CoA ligase [ADP-forming] subunit alpha, mitochondrial

COG0240 Glycerol-3-phosphate dehydrogenase [NAD(+)]

COG0277 Uncharacterized FAD-linked oxidoreductase Rv2280

COG0372 Citrate synthase (Fragment)

COG0427 Succinate CoA transferase

COG0538 Isocitrate dehydrogenase [NADP]

COG0554 Carbohydrate kinase

COG0667 Aldo/keto reductase

COG0674 Pyruvate synthase

COG0712 F1 complex, OSCP/delta subunit of ATPase

COG0822 NifU-like protein

COG1012 Aldehyde dehydrogenase (NAD+)

COG1012 Aldehyde-alcohol dehydrogenase

COG1012 Uncharacterized protein

COG1038 Pyruvate carboxylase

COG1062 Uncharacterized protein

COG1143 NADH-quinone oxidoreductase subunit I

COG1151 Putative carbon-monoxide dehydrogenase, catalytic subunit

COG1155 Uncharacterized protein

COG1274 Phosphoenolpyruvate carboxykinase [GTP]

COG1454 Alcohol dehydrogenase 2

COG1592 NADH peroxidase

COG1592 Reverse rubrerythrin

COG1592 Rubredoxin

COG1866 Phosphoenolpyruvate carboxykinase (ATP)

COG2025 Electron transfer flavoprotein subunit alpha

COG2033 Superoxide reductase

COG3288 NAD $(P)(+)$ transhydrogenase (Re/Si-specific) subunit alpha COG5023 Tubulin beta chain

\section{[L] Replication,_recombination_and_repair}

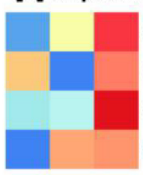

\section{COG0513 purine NTP-dependent helicase activity}

COG1204 helicase

COG0776 This protein is one of the two subunits of integration host factor

COG0188 DNA gyrase negatively supercoils closed circular

double-stranded DNA

[M] Cell_wall/membrane/envelope_biogenesis

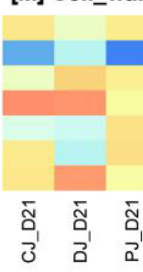

COG1004 UDP-glucose 6-dehydrogenase

ENOG411230Y Major outer membrane protein

COG1210 utp-glucose-1-phosphate uridylyltransferase

COG3203 Membrane

COG1089 GDP-mannose 4,6-dehydratase

COG1087 udp-glucose 4-epimerase

ENOG4111X18 major outer membrane protein OmpA

उ 3 वे

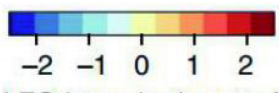

LFQ intensity (z-score)
[G] Carbohydrate_transport_and_metabolism

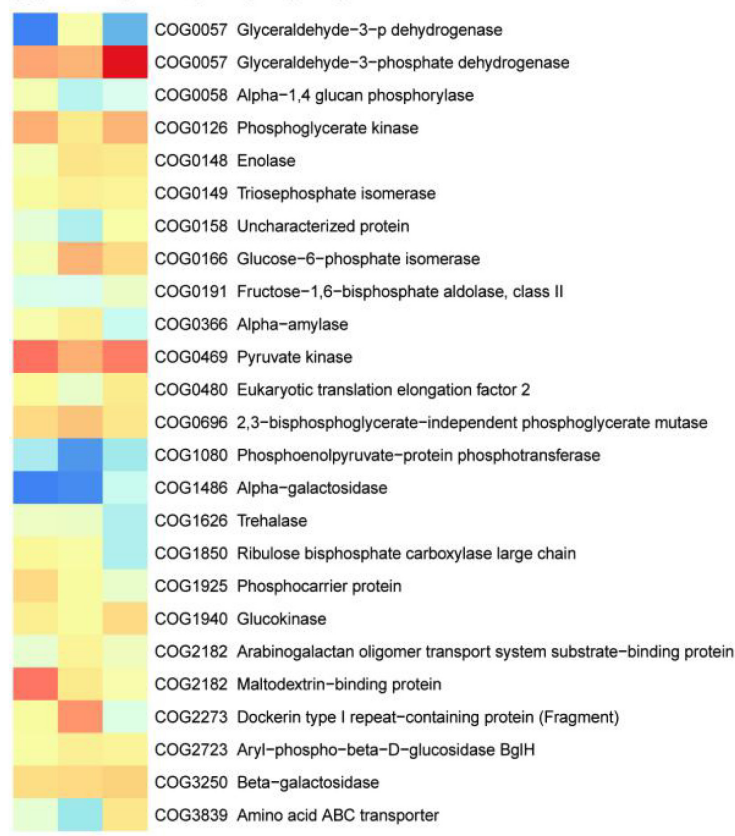

[J] Translation,_ribosomal_structure_and_biogenesis

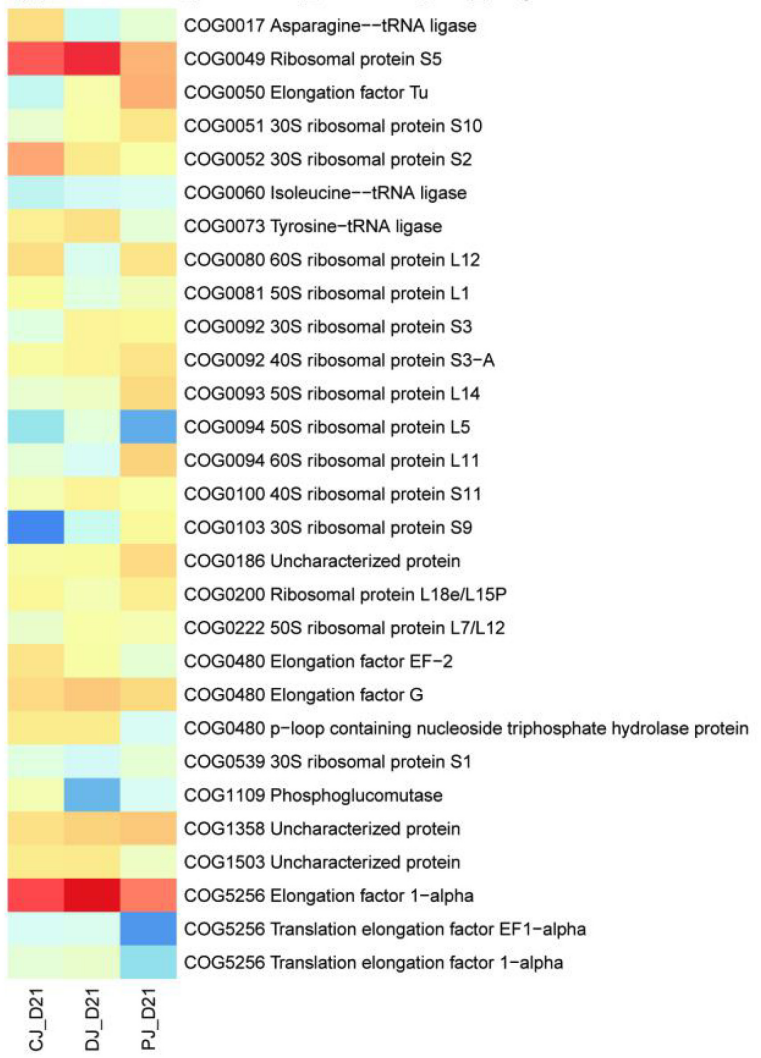

FIGURE 5 | Functional compositions of microbiome in neonatal calves infected by E. coli K99. Heatmap of differentially abundant COGs in neonatal calves. Representative COG categories are shown, and the colors indicate the average label free quantitation (LFQ) intensity for each subgroup of samples. Each row corresponds to a COG with the COG ID and the name indicated. 

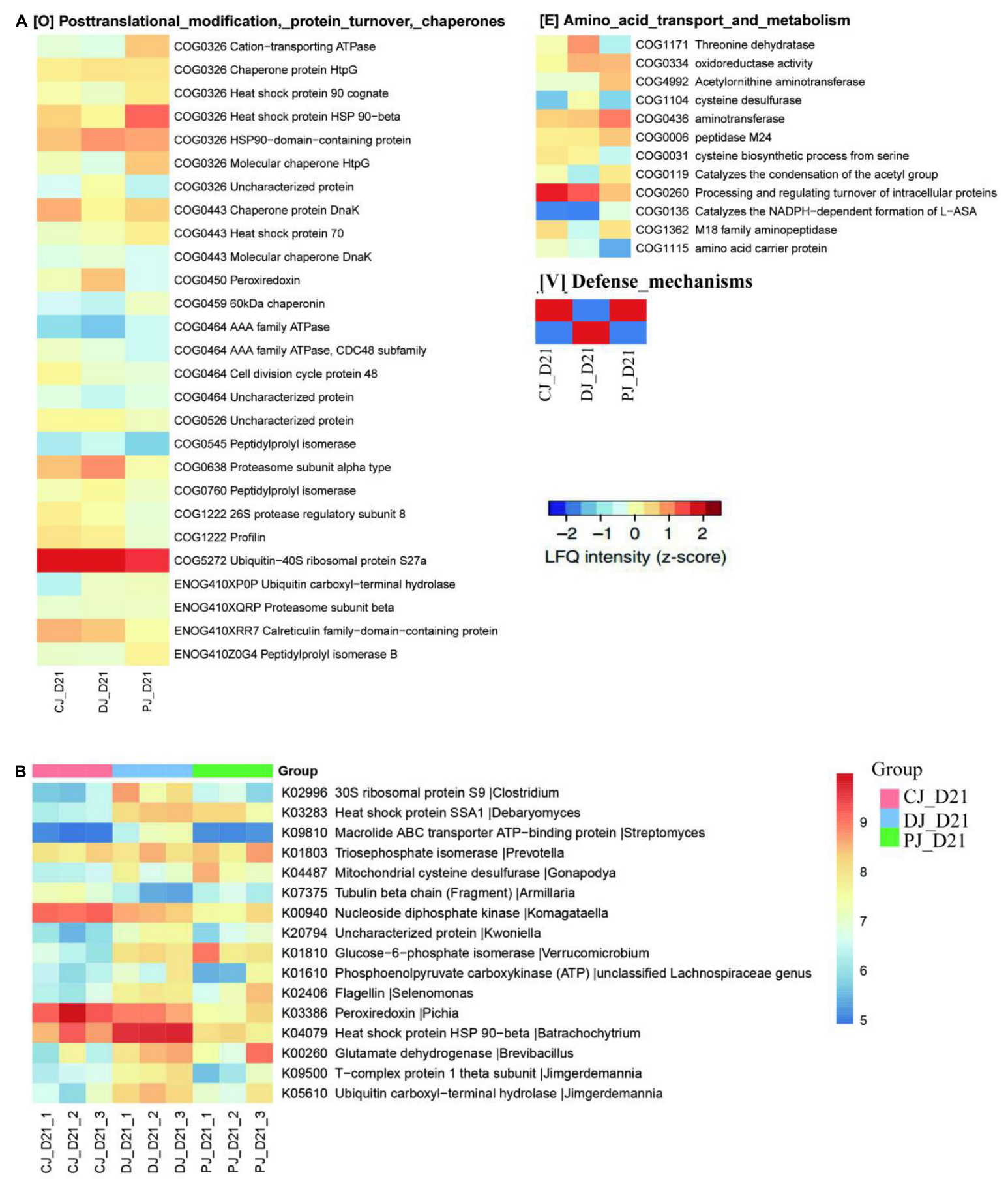

Group

K02996 30S ribosomal protein S9 |Clostridium K03283 Heat shock protein SSA1 |Debaryomyces

K09810 Macrolide ABC transporter ATP-binding protein [Streptomyces

K01803 Triosephosphate isomerase |Prevotella

K04487 Mitochondrial cysteine desulfurase |Gonapodya

K07375 Tubulin beta chain (Fragment) |Armillaria

K00940 Nucleoside diphosphate kinase |Komagataella

K20794 Uncharacterized protein |Kwoniella

K01810 Glucose-6-phosphate isomerase |Verrucomicrobium

K01610 Phosphoenolpyruvate carboxykinase (ATP) |unclassified Lachnospiraceae genus

K02406 Flagellin |Selenomonas

K03386 Peroxiredoxin |Pichia

K04079 Heat shock protein HSP 90-beta |Batrachochytrium

K00260 Glutamate dehydrogenase |Brevibacillus

K09500 T-complex protein 1 theta subunit |Jimgerdemannia

K05610 Ubiquitin carboxyl-terminal hydrolase |Jimgerdemannia

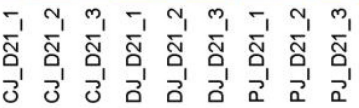

FIGURE 6 | Functional compositions of the microbiome in neonatal calves infected by E. coli K99. (A) Heatmap of differentially abundant COGs in neonatal calves. Representative COG categories are shown, and the colors indicate the average LFQ intensity for each subgroup of samples. Each row corresponds to a COG with the COG ID and name indicated. (B) Heatmap shows the average LFQ intensity for each group of samples. Each row represents one protein group, and the corresponding $\mathrm{KO} \mathrm{ID}, \mathrm{KO}$ name and taxonomic assignment are shown in the right panel.

of groups. We identified 55, 57 and 52 differentially abundant calf proteins for $\mathrm{C}$ vs. $\mathrm{D}, \mathrm{P}$ vs. D, and $\mathrm{P}$ vs. C, respectively (Supplementary Figure 2 and Supplementary Table 7). Among the differentially abundant calf proteins, 11 were upregulated and 12 were downregulated in the other groups compared with group
D. The proteins, Q3ZBF3, P62248, Q9XSC9, and Q3ZC02, in group $\mathrm{D}$ were significantly downregulated compared to those in $\mathrm{C}$, and the proteins, Q3ZBF3, Q3ZC02, and Q9XSC9, in group $\mathrm{P}$ were significantly upregulated compared to those in group D (Supplementary Table 7). 
A eggNOG Function Classification

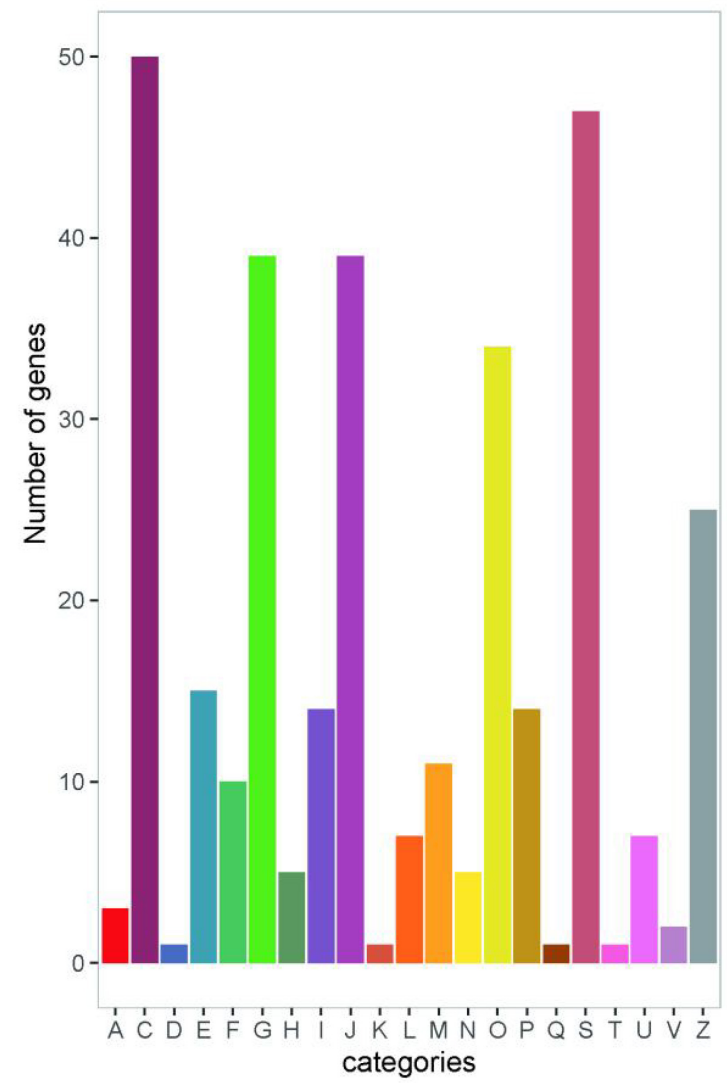

eggNOG_description

A:RNA_processing_and_modification

C:Energy_production_and_conversion

D:Cell_cycle_control,_cell_division,_chromosome_partitioning

E:Amino_acid_transport_and_metabolism

F:Nucleotide_transport_and_metabolism

G:Carbohydrate_transport_and_metabolism

$\mathrm{H}$ :Coenzyme_transport_and_metabolism

I:Lipid_transport_and_metabolism

$\mathrm{J}$ :Translation,_ribosomal_structure_and_biogenesis

K:Transcription

L:Replication,_recombination_and_repair

M:Cell_wall/membrane/envelope_biogenesis

$\mathrm{N}:$ Cell_motility

O:Posttranslational_modification,_protein_turnover,_chaperones

P:Inorganic_ion_transport_and_metabolism

Q:Secondary_metabolites_biosynthesis,_transport_and_catabolism

S:Function_unknown

$\mathrm{T}:$ Signal_transduction_mechanisms

U:Intracellular_trafficking,_secretion,_and_vesicular_transport

$\mathrm{V}$ :Defense_mechanisms

Z:Cytoskeleton

B
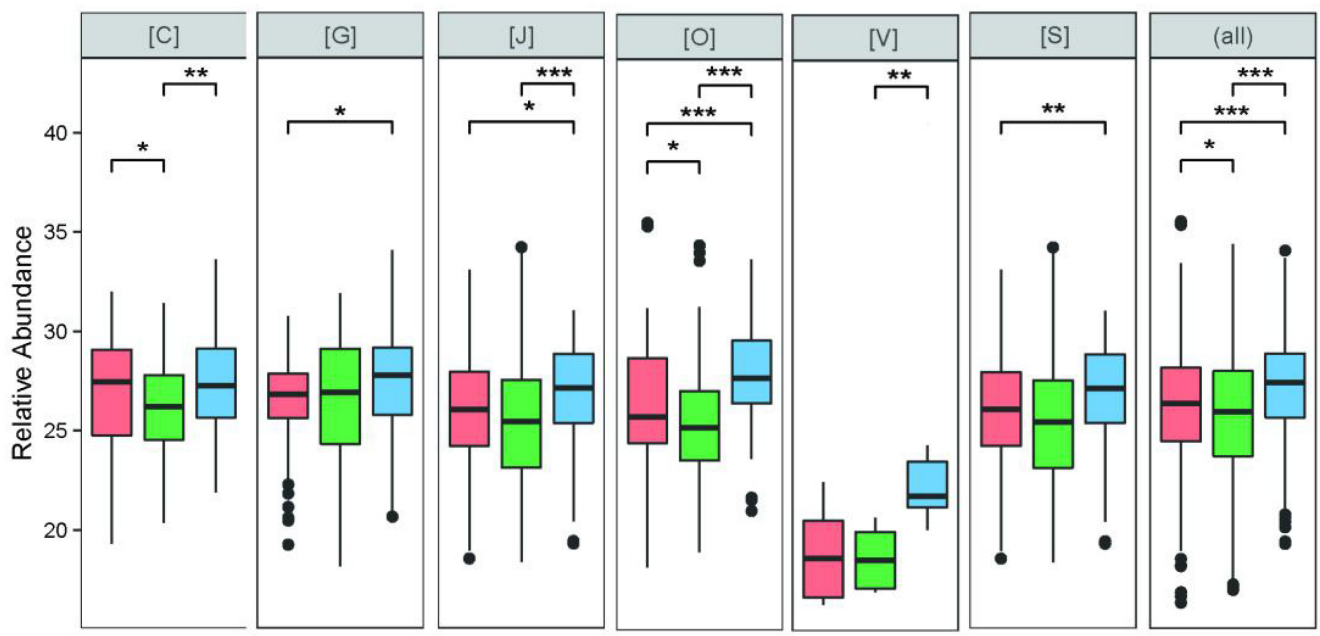

Group 追 CJ_D21 追 DJ_D21 户 PJ_D21

FIGURE 7 | (A) eggNOG classifications of the neonatal calves gut Metaproteomics. (B) LFQ intensity of COG category C (Energy production and conversion), category G (Carbohydrate transport and metabolism), category J (Translation, ribosomal structure and biogenesis), category O (Posttranslational modification, protein turnover, chaperones), and category V (Defense mechanisms) in microbiome of neonatal calves infected by E. coli K99. For the box plot, the bottom and top of the box represent the first and third quartiles, respectively. The middle line represents the sample median. Whiskers are drawn from the ends of the IQR to the furthest observations within 1.5 times the IQR range. Outliers $>1.5$ times the IQR are indicated with circle. ${ }^{*} p<0.05,{ }^{* *} p<0.01,{ }^{* * *} p<0.001$. 
Gene ontology enrichment analysis of differentially abundant calf proteins in $\mathrm{P}$ and $\mathrm{D}$ groups demonstrated that the most highly enriched biological functions involved metabolic and cellular processes (Supplementary Figure 4 and Supplementary Table 8).

To gain insights into host-microbiome interactions, we performed co-occurrence analysis for all identified differentially abundant calf proteins and microbial functions and found that both calf proteins and microbial functions were substantially associated with each other (Supplementary Figure 4). In the protein interaction networks (Supplementary Figure 4 and Supplementary Table 9), the microbial heat stress protein, HSPCOG 0326, which displayed the highest association $(n=5)$ with calf proteins, acted as an important microbial hub connecting the host and microbiome nodes, thereby suggesting a "hub" role for these proteins. As mentioned above, 54 of the 154 significantly increased microbial COGs belonged to categories $\mathrm{G}, \mathrm{O}$, and $\mathrm{V}$, which were related to energy production and conversion and DNA damage/mismatch responses, indicating that in calves, microbes are utilizing a considerable amount of energy production and conversion as well as defensive mechanisms against stressors derived by the host.

HSP90 is associated with five host proteins, and generates an inflammatory response via the necroptosis pathway, thereby facilitating the upregulation of IL-1 $\beta$ expression (KO4079). The microbial host-protein interaction map indicated that HSP90 was associated with the host protein, Q3MHN2, which participates in the immune system process and responds to stimuli affecting the host. Q3MHN2 contains a membrane attack complex (MAC)/perforin domain, and the MAC of the complement system is a well-characterized innate immune effector (Merselis et al., 2021). These findings proved that the relationship between neonatal calves infected by E. coli K99 and Batrachochytrium salamandrivorans may be at the strain level instead of at the species level, and that its sub-species level dysbiosis may be related to differences between immune functions in response to oxidative stress.

\section{DISCUSSION}

The diversity of intestinal microbiota showed a gradually increasing trend during the growth of newborn calves. Shannon diversity differs between animals of different ages (Alipour et al., 2018; Dias et al., 2018). The establishment of intestinal microflora in calves within 7 weeks of birth is closely related to calf health and growth (Oikonomou et al., 2013). Beta diversity decreased with age, while alpha diversity increasing (Dill-McFarland et al., 2019; Li et al., 2020). In addition, the Shannon and Chao1 indices showed significant changes in diversity from birth until the 8th week. Previous studies on dairy cows have shown that the Chao 1 index gradually increases with body weight over time from the 1st to the 7 th week before weaning. Older calves have a higher Chao 1 index (Oikonomou et al., 2013). Diarrhea or an infection may cause a decrease in microbial diversity (Kim et al., 2021; Xin et al., 2021). While most previous studies focused on investigating and interpreting calf manure samples, only a relatively few studies, such as ours, have focused on investigating the effects of feeding calves with compound probiotics on the intestinal microflora of these animals. The results of our current study on the diversity of microbiota in calf fecal samples were consistent with those of previous studies (Li et al., 2018, Dill-McFarland et al., 2019). Our results showed that the Chaol and Shannon indices of the fecal microbiota gradually changed over time. However, the diversity of microbiota in the small intestine of $\mathrm{D}$ calves was higher than that of the fungi, while Chaol and Shannon indices were lower than those of the $\mathrm{C}$ and $\mathrm{P}$ groups, in addition to which $\alpha$-diversity was significantly reduced. Thus, intestinal microbiota diversity of calves infected with E. coli can be significantly improved by adding compound probiotics.

However, calves have a large amount of mucosal-associated E. coli in their intestines in the first week after birth, which causes them to be more likely infected with pathogens. Therefore, reducing pathogen colonization and intestinal infections has become an effective way to improve intestinal health (Song et al., 2018). This study shows that Streptococcus and Enterococcus can use the available oxygen in the intestine and create an anaerobic environment, which is beneficial to the colonization of strict anaerobic intestinal residents such as Bifidobacterium and Bacteroides (Conroy et al., 2009). However, recent studies have indicated that gut microbiota possibly begin colonizing during the birth process (Malmuthuge et al., 2015; Song et al., 2018). The transmission process of maternal microbiota to newborn calves may originate at the amniotic fluid stage, in a manner similar to that reported for NB human infant gut microbiota (DiGiulio, 2012) and meconium (Moles et al., 2013). Significant individual variations observed among the NB calves may be due to variability in the transmission process from the mother cow to the birth environment (uterus, vaginal canal, and fetal membranes) (Klein-Jöbstl et al., 2019). The study found that the relative abundance of Lactobacillu and Shigella was higher in newborn calves than in D21 calves (Song et al., 2018).

E. coli infection can destroy the integrity of the intestinal tract and severely damage its intestinal function, thereby disrupting the balance of intestinal microbiota and leading to a decline in immune function (Dubreuil, 2017; Braz et al., 2020). Antibiotics play a vital role in many bacterial infections (Liu et al., 2017). However, antibiotics are known to cause intestinal microbiota imbalance, affect host metabolism, and lead to chronic inflammation (Scott et al., 2018). Relevant studies have shown that probiotics have a positive effect in reducing the susceptibility of calves to intestinal infections before weaning (Markowiak and Śliżewska, 2018; Mazloom et al., 2019; PlazaDiaz et al., 2019). The anti-diarrheal function of MSP may be associated with its role in immunity (Inatomi et al., 2017; Villot et al., 2020). Concentrations of circulating immunoglobulins, especially those of IgG, IgM, and IgA, are important indicators of immune function (Crassini et al., 2018). Some studies have indicated that supplementation with probiotics promotes the immune responsiveness of calves by improving serum IgG concentration (Song et al., 2019). Other studies have shown that supplementing with probiotics can reduce the rate of calf diarrhea and increase the serum IgM concentration on the 14th day, while 
increasing the serum IgA, IgG and IgM concentrations on the 28 day, respectively (Wang et al., 2019).

Intestinal SIgA has become the main regulator of intestinal microbiota through agglutination and enhancement of the opportunity to eliminate pathogens (Moor et al., 2017; Guo et al., 2020, 2021). Furthermore, Karamzadeh-Dehaghani et al. (2021) demonstrated that supplementation with probiotics improved the growth performance and immune response of calves. Consistent with these findings, we found that the gut SIgA concentration in the jejunum of calves in the MSP supplemented $\mathrm{P}$ group was increased by $86.48 \mu \mathrm{g} / \mathrm{g}$ compared to that in the $\mathrm{D}$ group. Studies have indicated that the regulation of potential intestinal pathogens and fungal colonization may enhance immunity (Nakawesi et al., 2020; Guo et al., 2021), whereas antibiotic exposure disturbs early GM, leading to intestinal dysbiosis and reduced SIgA (Guo et al., 2021), and that supplementation with additional probiotics may help enhance normal intestinal functioning (Tanaka et al., 2017; Plaza-Diaz et al., 2019; Roggero et al., 2020). The results of our study indicated that MSP supplementation improved the diversity and structure of the small intestinal microbiota in neonatal calves infected with E. coli K99, and simultaneously increased the secretion of SIgA compared to that in the antibiotics group.

The gut tract, which is one of the most microbiologically active ecosystems, plays a crucial role in the functioning of the mucosal immune system (MIS). Probiotics are known to exert positive effects on intestinal diseases. Among other effects, probiotics exert barrier-modulating effects and alter the inflammatory response toward pathogens in in vitro and in vivo intestinal infection models (Lodemann et al., 2017; Wang et al., 2019; Maldonado Galdeano et al., 2019), prevent or ameliorate damage to epithelial integrity caused by pathogenic challenge (Sherman et al., 2005; Johnson-Henry et al., 2008), and modulate the ease of cytokine secretion (Bahrami et al., 2011; Paszti-Gere et al., 2012). There is a close connection between the gut microbial community and the host immune system (Duparc et al., 2017; Cani and Jordan, 2018; Cani, 2019). Several reports have validated the fact that manipulating gut microbiota using probiotics, such as Bacillus subtilis (Jia et al., 2021) and Lactobacillus acidophilus (Lépine et al., 2018) may affect host gut barrier function and gut microbiota composition (Régnier et al., 2021). A growing number of studies have shown that certain probiotics (such as Lactobacillus acidophilus) can regulate the obstruction of intestinal epithelial fluid absorption and secretion caused by diarrhea (Borthakur et al., 2008; Singh et al., 2014). The results of the present study showed that MSP supplementation significantly upregulated relative mRNA expression of ZO-1, claudin-1, and occludin in the jejunum of E. coli-infected neonatal calves. Among them, a downward trend was observed in group D, indicating that in group P, claudin mRNA levels were increased to reduce intestinal E. coli adhesion, and to protect the mechanical barrier and paracellular permeability of the small intestine.

SCFA has important physiological effects on the host (Perego et al., 2018; Chen and Vitetta, 2019). Acetic acid is a short-chain fatty acid produced by intestinal bacteria. It inhibits the growth of pathogens and regulates the metabolism and gene expression of $\mathrm{B}$ cells, and promotes the secretion of SIgA, thereby maintaining and repairing the intestinal morphology of animals (Garcia et al., 2007; Kim et al., 2016; Wu et al., 2017; Bourassa et al., 2018). The results of this study indicate that MSP maintains intestinal health by increasing the acetic acid content in the jejunum of newborn calves infected with E. coli K99. Previous studies have shown that most Bacteroides, Bifidobacterium, Prevotella, and Rumenococci produce acetic acid through "pyruvate via the acetyl-CoA pathway" (Louis et al., 2014; Koh et al., 2016). In our study, the relative abundances of Bacteroides, Bifidobacterium, Prevotella, and Rumenococcus in the calf jejunum content of the MSP group was significantly higher than those of the antibiotic group. The results of this study indicated that MSP promotes the recovery of the intestinal function of calves following E. coli infection. Further, the results of this study are consistent with those of previous studies (Louis et al., 2014; Koh et al., 2016; Heeney et al., 2019).

Various functions of HSPs that target microbial stimuli include maintaining protein stability and functionality, activating, potent immune responses, immunomodulation of host-microbe relationships, and acting as biomarkers (diagnosis of infection) (Bolhassani and Agi, 2019). Various functions of HSPs that may be used to control bacterial infections have been studied (Bolhassani and Agi, 2019). Studies have shown that high expression of HSP90 may lead to the secretion of inflammatory cytokines in the body (Abaza, 2014). Studies have shown that some HSPs are effective inducers of innate and adaptive immunity. In addition, HSPs exert cytoprotection against inflammatory reactions by modulating inflammatory cascades which activate pro-inflammatory cytokines, such as TNF- $\alpha$, thus attenuating chronic inflammation (Zugel and Kaufmann, 1999; Ikwegbue et al., 2019). In our study, HSP expression levels which were further decreased in the $\mathrm{C}$ and $\mathrm{P}$ groups, were upregulated in group $\mathrm{D}$, thus alleviating diarrhea in neonatal calves. In agreement with the results of our study, Giri et al. (2018) and Kong et al. (2020) demonstrated that dietary supplementation with a probiotic mixture consisting of B. subtilis, L. acidophilus, and S. cerevisiae decreased the expression of HSP90 in in probiotic treated groups resulting in better growth and immunity.

Overexpression of HSP90S impairs the function of $\mathrm{T}$ cells, leading to a decrease in IL-2 expression (Bae et al., 2013). Enteric pathogens that invade a host are recognized by pattern recognition receptors (Kan et al., 2021). Probiotic supplementation can promote toll like receptors (TLR) to recognize various pathogens and activate NF- $\kappa B$. Then NF$\kappa \mathrm{B}$ is transferred to the nucleus to induce the expression of target genes, thereby regulating immune and inflammatory responses (Huebener and Schwabe, 2013; Elghandour et al., 2020). This study shows that probiotic supplementation can effectively down regulate IL- 1 in jejunal mucosa $\beta$, TNF- $\alpha$, and NF- - . The expression of B mRNA and inflammatory factors further indicates that probiotic supply can effectively resist $E$. coli infection by enhancing the intestinal innate immune function of newborn calves. This is consistent with the results of previous studies (Dong et al., 2019; Boranbayeva et al., 2020; Kan et al., 2021). However, some studies believe that the physiological functions of different probiotic strains are different (Kang and Im, 2015). Although the addition of probiotics can activate the 
TLR-NF- $\kappa$ B signaling pathway, the gene expression of IL- $1 \beta$ and TNF- $\alpha$ cytokines was not significantly affected (Wang et al., 2017). In conclusion, the gene expression of the TLR-NF- $\kappa B$ signaling pathway, pro-inflammatory cytokines, and heat shock protein in the jejunum of healthy newborn calves in group $\mathrm{D}$ in this article is down-regulated, indicating that antibiotic treatment of calves with diarrhea may reduce their immune levels and cause infections in the large intestine. The probiotic supplementation of bacillus new calves may focus on promoting the recovery of their intestinal function.

\section{CONCLUSION}

We demonstrated that supplementation with MSP promotes immune function and microbiota function in neonatal dairy calves. MSP supplementation significantly changed the microbial structure and diversity of the small intestine of calves infected with E. coli K99 MSP supplementation improved intestinal immune function, especially the production of SIgA and SCFA concentrations in the jejunum of infected calves, decreased the relative mRNA expression of $I L-1 \beta$ and TLR 4 and increased the relative mRNA expression of ZO-1 and occludin in the jejunal mucosa. Supplementation with MSP significantly enhanced intestinal energy metabolism and defense mechanisms of calves infected with E. coli K99 by reducing the expression of HSP90, which reduced inflammation and promoted the recovery of intestinal mucosal function. In view of these results, we recommend adding $2 \mathrm{~g} /$ day of MSP supplementation to the diets of dairy calves infected with E. coli K99. Our results are expected to provide a theoretical basis for the rational use of MSP supplements in calf production and provide substitutes for reducing the use of antibiotics.

\section{DATA AVAILABILITY STATEMENT}

The datasets presented in this study can be found in online repositories. The names of the repository/repositories and

\section{REFERENCES}

Abarenkov, K., Tedersoo, L., Nilsson, R. H., Vellak, K., Saar, I., Veldre, V., et al. (2010). PlutoF-a web based workbench for ecological and taxonomic research, with an online implementation for fungal ITS sequences. Evol. Bioinform. Online 6, 189-196. doi: 10.4137/EBO.S6271

Abaza, M. (2014). Heat shock proteins and parasitic diseases: part 1: helminths. Parasitol. United J. 7, 93-103.

Acres, S. D. (1985). Enterotoxigenic Escherichia coli infections in newborn calves: a review. J. Dairy Sci. 68, 229-256. doi: 10.3168/jds.S0022-0302(85)80814-6

Al Mawly, J., Grinberg, A., Prattley, D., Moffat, J., Marshall, J., and French, N. (2015). Risk factors for neonatal calf diarrhoea and enteropathogen shedding in New Zealand dairy farms. Vet. J. 203, 155-160. doi: 10.1016/j.tvjl.2015.01.010

Alipour, M. J., Jalanka, J., Pessa-Morikawa, T., Kokkonen, T., Satokari, R., Hynönen, U., et al. (2018). The compo-sition of the perinatal intestinal microbiota in cattle. Sci. Rep. 8:10437. doi: 10.1038/s41598-018-28733-y

Bae, J., Munshi, A., Li, C., Samur, M., Prabhala, R., Mitsiades, C., et al. (2013). Heat shock protein 90 is critical for regulation of phenotype and functional activity of human t lymphocytes and nk cells. J. Immunol. 190:3009. doi: 10. 4049/jimmunol.1200593 accession number(s) can be found in the article/Supplementary Material.

\section{ETHICS STATEMENT}

This study was approved by the Ethics Committee of the College of Animal Science and Technology, Shihezi University (Shihezi, China) (No. A2020-171-01).

\section{AUTHOR CONTRIBUTIONS}

YW and WZ: conceptualization, writing-original draft preparation. YW, CN, RL, HC, JN, CC, and XB: investigation, writing-review and editing. $\mathrm{YW}$ and $\mathrm{CN}$ : formal analysis. All authors have read and approved the final version of the manuscript.

\section{FUNDING}

This work was supported by the Key Scientific and Technological Research Project in Key Fields of Xinjiang Production and Construction Corps (No. 2018AB041), the Modern Agricultural Science and Technology Research and Achievement Transformation Project of the Eighth Division (No. 2018NY05), the Program for Science and Technology Innovation Talents in Xinjiang Production and Construction Corps (No. 2020CB023), and the Major Science and Technology Project of Xinjiang Production and Construction Corps (No. 2021AA004).

\section{SUPPLEMENTARY MATERIAL}

The Supplementary Material for this article can be found online at: https://www.frontiersin.org/articles/10.3389/fmicb. 2021.813245/full\#supplementary-material

Bahrami, B., Macfarlane, S., and Macfarlane, G. T. (2011). Induction of cytokine formation by human intestinal bacteria in gut epithelial cell lines. J. Appl. Microbiol. 110, 353-363. doi: 10.1111/j.1365-2672.2010.04889.x

Bi, Y., Tu, Y., Zhang, N., Wang, S., Zhang, F., Suen, G., et al. (2021). Multiomics analysis reveals the presence of a microbiome in the gut of fetal lambs. Gut 70, 853-864. doi: 10.1136/gutjnl-2020-320951

Bitla, S., Gayatri, A. A., Puchakayala, M. R., Kumar Bhukya, V., Vannada, J., Dhanavath, R., et al. (2021). Design and synthesis, biological evaluation of bis$(1,2,3$ - and 1,2,4)-triazole derivatives as potential antimicrobial and antifungal agents. Bioorg. Med. Chem. Lett. 41:128004. doi: 10.1016/j.bmcl.2021.128004

Bolhassani, A., and Agi, E. (2019). Heat shock proteins in infection. Clin. Chim. Acta 498, 90-100. doi: 10.1016/j.cca.2019.08.015

Boranbayeva, T., Karahan, A. G., Tulemissova, Z., Myktybayeva, R., and Özkaya, S. (2020). Properties of a New probiotic candidate and lactobacterin-TK2 against diarrhea in calves. Probiotics Antimicrob. Proteins 12, 918-928. doi: 10.1007/ s12602-020-09649-4

Borthakur, A., Gill, R. K., Tyagi, S., Koutsouris, A., Alrefai, W. A., Hecht, G. A., et al. (2008). The probiotic Lactobacillus acidophilus stimulates chloride/hydroxyl exchange activity in human intestinal epithelial cells. J. Nutr. 138, 1355-1359. doi: $10.1093 /$ jn/138.7.1355 
Bourassa, D. V., Wilson, K. M., Ritz, C. R., Kiepper, B. K., and Buhr, R. J. (2018). Evaluation of the addition of organic acids in the feed and/or water for broilers and the subsequent recovery of Salmonella typhimurium from litter and ceca. Poult. Sci. 97, 64-73. doi: 10.3382/ps/pex289

Braz, V. S., Melchior, K., and Moreira, C. G. (2020). Escherichia coli as a multifaceted pathogenic and versatile bacterium. Front. Cell Infect. Microbiol. 10:548492. doi: 10.3389/fcimb.2020.548492

Brunauer, M., Roch, F. F., and Conrady, B. (2021). Prevalence of worldwide neonatal calf diarrhoea caused by bovine rotavirus in combination with bovine coronavirus, Escherichia coli $\mathrm{K} 99$ and Cryptosporidium spp.: a meta-analysis. Animals (Basel) 11:1014. doi: 10.3390/ani11041014

Bulgin, M. S., Anderson, B. C., Ward, A. C. S., and Evermann, J. F. (1982). Infectious agents associated with neonatal calf disease in southwestern Idaho and eastern Oregon. J. Am. Vet. Med. Assoc. 180, 1222-1226.

Bywater, R. J., and Logan, E. F. (1974). The site and characteristics of intestinal water and electrolyte loss in Escherichia coli-induced diarrhoea in calves. J. Comp. Pathol. 84, 599-610. doi: 10.1016/0021-9975(74)90051-6

Cani, P. D. (2019). Severe obesity and gut microbiota: does bariatric surgery really reset the system? Gut 68, 5-6. doi: 10.1136/gutjnl-2018-316815

Cani, P. D., and Jordan, B. F. (2018). Gut microbiota-mediated inflammation in obesity: a link with gastrointestinal cancer. Nat. Rev. Gastroenterol. Hepatol. 15, 671-682. doi: 10.1038/s41575-018-0025-6

Chen, J., and Vitetta, L. (2019). Activation of t-regulatory cells by a synbiotic may be important for its anti-inflammatory effect. Eur. J. Nutr. 58, 3379-3380. doi: 10.1007/s00394-019-02080-8

Chiaro, T. R., Soto, R., Zac Stephens, W., Kubinak, J. L., Petersen, C., Gogokhia, L., et al. (2017). A member of the gut mycobiota modulates host purine metabolism exacerbating colitis in mice. Sci. Transl. Med. 9:eaaf9044. doi: 10. 1126/scitranslmed.aaf9044

Cho, Y.-I. I., and Yoon, K.-J. J. (2014). An overview of calf diarrhea-Infectious etiology, diagnosis, and intervention. J. Vet. Sci. 15, 1-17. doi: 10.4142/jvs.2014. 15.1 .1

Cole, J. R., Wang, Q., Cardenas, E., Fish, J., Chai, B., Farris, R. J., et al. (2009). The ribosomal database project: improved alignments and new tools for rRNA analysis. Nucleic Acids Res. 37, D141-D145. doi: 10.1093/nar/gkn879

Collinson, S., Deans, A., Padua-Zamora, A., Gregorio, G. V., Li, C., Dans, L. F., et al. (2020). Probiotics for treating acute infectious diarrhoea. Cochrane Datab. Syst. Rev. 12:CD003048. doi: 10.1002/14651858.CD003048.pub4

Conroy, M. E., Shi, H. N., and Walker, W. A. (2009). Long-term health effects of the neonatal microbialmicrobiota. Curr. Opin. Allergy Clin. Immunol. 9, 197-201. doi: 10.1097/ACI.0b013e32832b3f1d

Crassini, K. R., Zhang, E., Balendran, S., Freeman, J. A., Best, O. G., Forsyth, C. J., et al. (2018). Humoral immune failure defined by immunoglobulin class and immunoglobulin G subclass deficiency is associated with shorter treatment-free and overall survival in chronic lymphocytic leukaemia. Br. J. Haematol. 181, 97-101. doi: 10.1111/bjh.15146

da Silva Medeiros, T. N., Lorenzetti, E., Alfieri, A. F., and Alfieri, A. A. (2015). Phylogenetic analysis of a G6P[5] bovine rotavirus strain isolated in a neonatal diarrhea outbreak in a beef cattle herd vaccinated with G6P[1] and G10P[11] genotypes. Arch. Virol. 160, 447-451. doi: 10.1007/s00705-014-2271-4

Dahlgren, D., Sjöblom, M., Hellström, P. M., and Lennernäs, H. (2021). Chemotherapeutics-induced intestinal mucositis: pathophysiology and potential treatment strategies. Front. Pharmacol. 12:681417. doi: 10.3389/fphar.2021.681417

Dias, J., Marcondes, M. I., De Souza, S. M., Silva, B. C. D. M. E., Noronha, M. F., Resende, R. T., et al. (2018). Bacterial community dynamics across the gastrointestinal tracts of dairy calves during preweaning development. Appl. Environ. Microbiol. 84:e02675-17. doi: 10.1128/AEM.02675-17

DiGiulio, D. B. (2012). Diversity of microbes in amniotic fluid. Semin. Fetal Neonatal Med. 17, 2-11. doi: 10.1016/j.siny.2011.10.001

Dill-McFarland, K. A., Weimer, P. J., Breaker, J. D., and Suen, G. (2019). Diet inflfluences early microbiota development in dairy calves without long-term impacts on milk production. Appl. Environ. Microbiol. 85:e02141-18. doi: 10. 1128/AEM.02141-18

Dong, Y., Zhang, F., Wang, B., Gao, J., Zhang, J., and Shao, Y. (2019). Laboratory evolution assays and whole-genome sequencing for the development and safety evaluation of lactobacillus plantarum with stable resistance to gentamicin. Front Microbiol. 10:1235. doi: 10.3389/fmicb.2019.01235
Dubreuil, J. D. (2017). Enterotoxigenic Escherichia coli targeting intestinal epithelial tight junctions: An effective way to alter the barrier integrity. Microb. Pathogen. 113, 129-134. doi: 10.1016/j.micpath.2017.10.037

Duparc, T., Plovier, H., Marrachelli, V. G., Van Hul, M., Essaghir, A., Ståhlman, M., et al. (2017). Hepatocyte MyD88 affects bile acids, gut microbiota and metabolome contributing to regulate glucose and lipid metabolism. Gut 66, 620-632. doi: 10.1136/gutjnl-2015-310904

Edgar, R. C. (2013). UPARSE: highly accurate OTU sequences from microbial amplicon reads. Nat. Methods 10, 996-998. doi: 10.1038/nmeth.2604

Egertson, J. D., MacLean, B., Johnson, R., Xuan, Y., and MacCoss, M. J. (2015). Multiplexed peptide analysis using data-independent acquisition and Skyline. Nat. Protoc. 10, 887-903. doi: 10.1038/nprot.2015.055

Elghandour, M., Tan, Z. L., Abu Hafsa, S. H., Adegbeye, M. J., Greiner, R., Ugbogu, E. A., et al. (2020). Saccharomyces cerevisiae as a probiotic feed additive to non and pseudo-ruminant feeding: a review. J. Appl. Microbiol. 128, 658-674. doi: $10.1111 /$ jam. 14416

Garcia, V., Catala-Gregori, P., Hernandez, F., Megias, M. D., and Madrid, J. (2007). Efffect of formic acid and plant extracts on growth, nutrient digestibility, intestine mucosa morphology, and meat yield of broilers. J. Appl. Poultry Res. 16, 555-562. doi: 10.3382/japr.2006-00116

Giri, S. S., Yun, S., Jun, J. W., Kim, H. J., Kim, S. G., Kang, J. W., et al. (2018). Therapeutic effect of intestinal autochthonous Lactobacillus reuteri $\mathrm{P} 16$ against waterborne lead toxicity in Cyprinus carpio. Front. Immunol. 9:1824.

González Pasayo, R. A., Sanz, M. E., Padola, N. L., and Moreira, A. R. (2019). Phenotypic and genotypic characterization of enterotoxigenic Escherichia coli isolated from diarrheic calves in Argentina. Open Vet. J. 9, 65-73. doi: 10.4314/ ovj.v9i1.12

Gulliksen, S. M., Jor, E., Lie, K. I. I, Hamnes, S., Loken, T., Akerstedt, J., et al. (2009). Enteropathogens and risk factors for diarrhea in Norwegian dairy calves. J. Dairy Sci. 92, 5057-5066. doi: 10.3168/jds.2009-2080

Guo, J., Huang, W., Han, X., You, Y., and Jicheng, Z. (2020). Interaction between IgA and gut microbiota and its role in control ling metabolic syndrome. Obesity Rev. 22, 1-15. doi: 10.1111/obr.13155

Guo, J., Ren, C., Han, X., Huang, W., You, Y., and Zhan, J. (2021). Role of IgA in the early-life establishment of the gut microbiota and immunity: Implications for constructing a healthy start. Gut Microbes 13, 1-21. doi: 10.1080/19490976. 2021.1908101

Heeney, D. D., Zhai, Z., Bendiks, Z., Barouei, J., Martinic, A., Slupsky, C., et al. (2019). Lactobacillus plantarum bacteriocin is associated with intestinal and systemic improvements in diet-induced obese mice and maintains epithelial barrier integrity in vitro. Gut Microbes 10, 382-397. doi: 10.1080/19490976. 2018.1534513

Hrala, M., Bosák, J., Micenková, L., Křenová, J., Lexa, M., Pirková, V., et al. (2021). Escherichia coli strains producing selected Bacteriocins inhibit porcine enterotoxigenic Escherichia coli (ETEC) under both in vitro and in vivo conditions. Appl. Environ. Microbiol. 87:e0312120. doi: 10.1128/AEM.03121-20

Hu, J., Chen, L., Zheng, W., Shi, M., Liu, L., Xie, C., et al. (2018). Lactobacillus frumenti facilitates intestinal epithelial barrier function maintenance in earlyweaned piglets. Front. Microbiol. 9:897. doi: 10.3389/fmicb.2018.00897

Hubert, J., Erban, T., Kopecky, J., Sopko, B., Nesvorna, M., Lichovnikova, M., et al. (2017). Comparison of microbiomes between red poultry mite populations (Dermanyssus gallinae): predominance of Bartonella-like bacteria. Microb. Ecol. 74, 947-960. doi: 10.1007/s00248-017-0993-z

Huebener, P., and Schwabe, R. F. (2013). Regulation of wound healing and organ fibrosis by toll-like receptors. Biochim. Biophys. Acta 1832, 1005-1017. doi: 10.1016/j.bbadis.2012.11.017

Huson, D. H., Auch, A. F., Qi, J., and Schuster, S. C. (2007). MEGAN analysis of metagenomic data. Genome Res. 17, 377-386. doi: 10.1101/gr.5969107

Ikwegbue, P. C., Masamba, P., Mbatha, L. S., Oyinloye, B. E., and Kappo, A. P. (2019). Interplay between heat shock proteins, inflammation and cancer: a potential cancer therapeutic target. Am. J. Cancer Res. 9, 242-249.

Inatomi, T., Amatatsu, M., Romero-Pérez, G. A., Inoue, R., and Tsukahara, T. (2017). Dietary probiotic compound improves reproductive performance of porcine epidemic diarrhea virus-infected sows reared in a Japanese commercial swine farm under vaccine control condition. Front. Immunol. 8:1877. doi: 10. 3389/fimmu.2017.01877

Izzo, M. M., Kirkland, P. D., Mohler, V. L., Perkins, N. R., Gunn, A. A., and House, J. K. (2011). Prevalence of major enteric pathogens in Australian dairy calves 
with diarrhoea. Aust. Vet. J. 89, 167-173. doi: 10.1111/j.1751-0813.2011.00 692.x

Jia, R., Sadiq, F. A., Liu, W., Cao, L., and Shen, Z. (2021). Protective effects of Bacillus subtilis ASAG 216 on growth performance, antioxidant capacity, gut microbiota and tissues residues of weaned piglets fed deoxynivalenol contaminated diets. Food Chem. Toxicol. 148:111962. doi: 10.1016/j.fct.2020. 111962

Johnson-Henry, K. C., Donato, K. A., Shen-Tu, G., Gordanpour, M., and Sherman, P. M. (2008). Lactobacillus rhamnosus strain GG prevents enterohemorrhagic Escherichia coli O157:H7-induced changes in epithelial barrier function. Infect. Immun. 76, 1340-1348. doi: 10.1128/IAI.00778-07

Kan, L., Guo, F., Liu, Y., Pham, V. H., Guo, Y., and Wang, Z. (2021). Probiotics Bacillus licheniformis improves intestinal health of subclinical necrotic enteritischallenged broilers. Front. Microbiol. 12:623739. doi: 10.3389/fmicb.2021. 623739

Kanehisa, M., Sato, Y., and Morishima, K. (2016). BlastKOALA and GhostKOALA: KEGG tools for functional characterization of genome and metagenome sequences. J. Mol. Biol. 428, 726-731. doi: 10.1016/j.jmb.2015.11.006

Kang, H. J., and Im, S. H. (2015). Probiotics as an immune modulator. J. Nutr. Sci. Vitaminol. (Tokyo) 61, S103-S105. doi: 10.3177/jnsv.61.S103

Karamzadeh-Dehaghani, A., Towhidi, A., Zhandi, M., Mojgani, N., and FouladiNashta, A. (2021). Combined effect of probiotics and specific immunoglobulin Y directed against Escherichia coli on growth performance, diarrhea incidence, and immune system in calves. Animal 15:100124. doi: 10.1016/j.animal.2020. 100124

Kim, E. T., Lee, S. J., Kim, T. Y., Lee, H. G., Atikur, R. M., Gu, B. H., et al. (2021). Dynamic changes in fecal microbial communities of neonatal dairy calves by aging and diarrhea. Animals (Basel) 11:1113. doi: 10.3390/ani11041113

Kim, M., Qie, Y., Park, J., and Kim, C. H. (2016). Gut microbial metabolites fuel host antibody responses. Cell Host Microbe 20, 202-214. doi: 10.1016/j.chom. 2016.07.001

Klein-Jöbstl, D., Quijada, N. M., Dzieciol, M., Feldbacher, B., Wagner, M., Drillich, M., et al. (2019). Microbiota of newborn calves and their mothers reveals possible transfer routes for newborn calves' gastrointestinal microbiota. PLoS One 14:e220554. doi: 10.1371/journal.pone.0220554

Klein-Jöbstl, D., Schornsteiner, E., Mann, E., Wagner, M., Drillich, M., and Schmitz-Esser, S. (2014). Pyrosequencing reveals diverse fecal microbiota in Simmental calves during early development. Front. Microbiol. 5:622. doi: 10. 3389/fmicb.2014.00622

Koh, A., De Vadder, F., Kovatcheva-Datchary, P., and Bäckhed, F. (2016). From dietary fiber to host physiology: short-chain fatty acids as key bacterial metabolites. Cell 165, 1332-1345. doi: 10.1016/j.cell.2016.05.041

Kong, Y., Gao, C., Du, X., Zhao, J., Li, M., Shan, X., et al. (2020). Effects of single or conjoint administration of lactic acid bacteria as potential probiotics on growth, immune response and disease resistance of snakehead fish (Channa argus). Fish Shellfish Immunol. 102, 412-421. doi: 10.1016/j.fsi.2020.0 5.003

Krogh, H. V. (1983). Occurrence of enterotoxigenic Escherichia coli in calves with acute neonatal diarrhoea. Nord. Vet. Med. 35, 346-352.

Lépine, A., de Wit, N., Oosterink, E., Wichers, H., Mes, J., and de Vos, P. (2018). Lactobacillus acidophilus attenuates Salmonella-induced stress of epithelial cells by modulating tight-junction genes and cytokine responses. Front. Microbiol. 9:1439. doi: 10.3389/fmicb.2018.01439

Li, H., Limenitakis, J. P., Greiff, V., Yilmaz, B., Schären, O., Urbaniak, C., et al. (2020). Mucosal or systemic microbiota exposures shape the B cell repertoire. Nature 584, 274-278. doi: 10.1038/s41586-020-2564-6

Li, M., Chen, Z., Wu, T., and Lu, J. (2018). Li2S- or S-based lithium-ion batteries. Adv. Mater. 30:e1801190. doi: 10.1002/adma.201801190

Liu, B., Yuan, J., Yiu, S. M., Li, Z., Xie, Y., Chen, Y., et al. (2012). COPE: an accurate k-mer-based pair-end reads connection tool to facilitate genome assembly. Bioinformatics 28, 2870-2874. doi: 10.1093/bioinformatics/bts563

Liu, Y., Ji, P., Lv, H., Qin, Y., and Deng, L. (2017). Gentamicin modified chitosan film with improved antibacterial property and cell biocompatibility. Int. J. Biol. Macromol. 98, 550-556. doi: 10.1016/j.ijbiomac.2017.01.121

Lodemann, U., Amasheh, S., Radloff, J., Kern, M., Bethe, A., Wieler, L. H., et al. (2017). Effects of ex vivo infection with ETEC on jejunal barrier properties and cytokine expression in probiotic-supplemented pigs. Dig. Dis. Sci. 62, 922-933. doi: 10.1007/s10620-016-4413-x
Louis, P., Hold, G. L., and Flint, H. J. (2014). The gut microbiota, bacterial metabolites and colorectal cancer. Nat. Rev. Microbiol. 12, 661-672. doi: 10. 1038/nrmicro3344

Maldonado Galdeano, C., Cazorla, S. I., Lemme Dumit, J. M., Vélez, E., and Perdigón, G. (2019). Beneficial effects of probiotic consumption on the immunesystem. Ann. Nutr. Metab. 74, 115-124. doi: 10.1159/000496426

Malmuthuge, N., Griebel, P. J., and Guan, L. (2015). The gut microbiome and its potential role in the development and function of newborn calf gastrointestinal tract. Front. Vet. Sci. 2:36. doi: 10.3389/fvets.2015.00036

Malmuthuge, N., and Guan, L. L. (2017). Understanding the gut microbiome of dairy calves: opportunities to improve early-life gut health. J. Dairy Sci. 100, 5996-6005. doi: 10.3168/jds.2016-12239

Markowiak, P., and Śliżewska, K. (2018). The role of probiotics, prebiotics and synbiotics in animal nutrition. Gut Pathog. 10:21. doi: 10.1186/s13099-0180250-0

Mazloom, K., Siddiqi, I., and Covasa, M. (2019). Probiotics: how effffective are they in the fight against obesity? Nutrients 11:258. doi: 10.3390/nu11020258

Memon, F. U., Yang, Y., Leghari, I. H., Lv, F., Soliman, A. M., Zhang, W., et al. (2021). Transcriptome analysis revealed ameliorative effects of bacillus based probiotic on immunity, gut barrier system, and metabolism of chicken under an experimentally induced Eimeria tenella Infection. Genes 12:536. doi: 10.3390/ genes12040536

Merselis, L. C., Rivas, Z. P., and Munson, G. P. (2021). Breaching the bacterial envelope: the pivotal role of perforin-2 (MPEG1) within phagocytes. Front. Immunol. 12:597951. doi: 10.3389/fimmu.2021.597951

Moles, L., Gómez, M., Heilig, H., Bustos, G., Fuentes, S., de Vos, W., et al. (2013). Bacterial diversity in meconium of preterm neonates and evolution of their fecal microbiota during the first month of life. PLoS One 8:e66986. doi: 10.1371/journal.pone.0066986

Moon, H. W., McClurkin, A. W., Isaacson, R. E., Pohlenz, J., Skartvedt, S. M., Gillette, K. G., et al. (1978). Pathogenic relationships of rotavirus, Escherichia coli, and other agents in mixed infections in calves. J. Am. Vet. Med. Assoc. 173, 577-583.

Moor, K., Diard, M., Sellin, M. E., Felmy, B., Wotzka, S. Y., Toska, A., et al. (2017). High-avidity IgA protects the intestine by enchaining growing bacteria. Nature 544, 498-502. doi: 10.1038/nature22058

Nakawesi, J., This, S., Hütter, J., Boucard-Jourdin, M., Barateau, V., Muleta, K. G., et al. (2020). $\alpha v \beta 8$ integrin-expression by BATF3-dependent dendritic cells facilitates early IgA responses to Rotavirus. Mucosal Immunol. 14, 53-67. doi: 10.1038/s41385-020-0276-8

Oikonomou, G., Teixeira, A. G., Foditsch, C., Bichalho, M. L., Machado, V. S., and Bicalho, R. C. (2013). Fecal microbial diversity in pre-weaned dairy calves as described by pyrosequencing of metagenomic 16S rDNA. Associations of Faecalibacterium species with health and growth. PLoS One 8:e63157. doi: 10.1371/journal.pone.0063157

Paszti-Gere, E., Szeker, K., Csibrik-Nemeth, E., Csizinszky, R., Marosi, A., Palocz, O., et al. (2012). Metabolites of Lactobacillus plantarum 2142 prevent oxidative stress-induced overexpression of proinflammatory cytokines in IPEC-J2 cell line. Inflammation 35, 1487-1499. doi: 10.1007/s10753-012-9462-5

Perego, S., Sansoni, V., Banfi, G., and Lombardi, G. (2018). Sodium butyrate has anti-proliferative, pro-differentiating, and immunomodulatory effects in osteosarcoma cells and counteracts the TNF $\alpha$-induced low-grade inflammation. Int. J. Immunopathol. Pharmacol. 32:394632017752240. doi: $10.1177 / 0394632017752240$

Pfaffl, M. W. (2001). A new mathematical model for relative quantification in real-time RTPCR. Nucleic Acids Res. 29, 900-905. doi: 10.1093/nar/29.9.e45

Plaza-Diaz, J., Ruiz-Ojeda, F. J., Gil-Campos, M., and Gil, A. (2019). Mechanisms of action of probiotics. Adv Nutr. 10, S49-S66. doi: 10.1093/advances/nmy063

Raheem, A., Liang, L., Zhang, G., and Cui, S. (2021). Modulatory effects of probiotics during pathogenic infections with emphasis on immune regulation. Front. Immunol. 12:616713. doi: 10.3389/fimmu.2021.616713

Régnier, M., Van Hul, M., Knauf, C., and Cani, P. D. (2021). Gut microbiome, endocrine control of gut barrier function and metabolic diseases. J. Endocrinol. 248, R67-R82. doi: 10.1530/JOE-20-0473

Roggero, P., Liotto, N., Pozzi, C., Braga, D., Troisi, J., Menis, C., et al. (2020). Analysis of immune, microbiota and metabolome maturation in infants in a clinical trial of Lactobacillus paracasei CBA L74-fermented formula. Nat. Commun. 11:2703. 
Roth, B. A., Keil, N. M., Gygax, L., and Hillmann, E. (2009). Influence of weaning method on health status and rumen development in dairy calves. J. Dairy Sci. 92, 645-656. doi: 10.3168/jds.2008-1153

Runnels, P. L., Moon, H. W., and Schneider, R. A. (1980). Development of resistance with host age to adhesion of $\mathrm{K} 99+$ Escherichia coli to isolated intestinal epithelial cells. Infect. Immun. 28, 298-300.

Sambanthamoorthy, K., Feng, X., Patel, R., Patel, S., and Paranavitana, C. (2014). Antimicrobial and antibiofifilm potential of biosurfactants isolated from lactobacilli against multi-drug-resistant pathogens. BMC Microbiol. 14:197. doi: 10.1186/1471-2180-14-197

Sanchez, B., Urdaci, M. C., and Margolles, A. (2010). Extracellular proteins secreted by probiotic bacteria as mediators of effects that promote mucosabacteria interactions. Microbiology 156, 3232-3242. doi: 10.1099/mic.0.044057-0

Schäff, C. T., Gruse, J., Maciej, J., Pfuhl, R., Zitnan, R., Rajsky, M., et al. (2018). Effects of feeding unlimited amounts of milk replacer for the first 5 weeks of age on rumen and small intestinal growth and development in dairy calves. J. Dairy Sci. 101, 783-793. doi: 10.3168/jds.2017-13247

Schloss, P. D., Westcott, S. L., Ryabin, T., Hall, J. R., Hartmann, M., Hollister, E. B., et al. (2009). Introducing mothur: open-source, platform-independent, community supported software for describing and comparing microbial communities. Appl. Environ. Microbiol. 75, 7537-7541. doi: 10.1128/AEM. 01541-09

Scott, N. A., Andrusaite, A., Andersen, P., Lawson, M., Alcon-Giner, C., Leclaire, C., et al. (2018). Antibiotics induce sustained dysregulation of intestinal $\mathrm{T}$ cell immunity by perturbing macrophage homeostasis. Sci. Transl. Med. 10:eaao4755. doi: 10.1126/scitranslmed.aao4755

Shen, Z., Mustapha, A., Lin, M., and Zheng, G. (2017). Biocontrol of the internalization of Salmonella enterica and Enterohaemorrhagic Escherichia coli in mung bean sprouts with an endophytic Bacillus subtilis. Int. J. Food Microbiol. 250, 37-44. doi: 10.1016/j.ijfoodmicro.2017.03.016

Sherman, P. M., Johnson-Henry, K. C., Yeung, H. P., Ngo, P. S., Goulet, J., and Tompkins, T. A. (2005). Probiotics reduce enterohemorrhagic Escherichia coli O157:H7 - and enteropathogenic E. coli O127:H6-induced changes in polarized T84 epithelial cell monolayers by reducing bacterial adhesion and cytoskeletal rearrangements. Infect. Immun. 73, 5183-5188.

Singh, V., Kumar, A., Raheja, G., Anbazhagan, A. N., Priyamvada, S., Saksena, S., et al. (2014). Lactobacillus acidophilus attenuates downregulation of DRA function and expression in inflammatory models. Am. J. Physiol. Gastrointest. Liver Physiol. 307, G623-G631. doi: 10.1152/ajpgi.00104.2014

Song, L., Qiao, X., Zhao, D., Xie, W., Bukhari, S. M., Meng, Q., et al. (2019). Effects of Lactococcus lactis MG1363 producing fusion proteins of bovine lactoferricin-lactoferrampin on growth, intestinal morphology and immune function in weaned piglet. J. Appl. Microbiol. 127, 856-866. doi: 10.1111/jam. 14339

Song, Y., Malmuthuge, N., Steele, M. A., and Guan, L. L. (2018). Shift of hindgut microbiota and microbial short chain fatty acids profiles in dairy calves from birth to pre-weaning. FEMS Microbiol Ecol. 94:fix179. doi: 10.1093/femsec/ fix179

Sunderland, S. J., Sarasola, P., Rowan, T. G., Giles, C. J., and Smith, D. G. (2003). Efficacy of danofloxacin $18 \%$ injectable solution in the treatment of Escherichia coli diarrhoea in young calves in Europe. Res. Vet. Sci. 74, 171-178. doi: 10.1016/ s0034-5288(02)00186-8

Szklarczyk, D., Morris, J. H., Cook, H., Kuhn, M., Wyder, S., Simonovic, M., et al. (2017). The STRING database in 2017: quality-controlled protein-protein association networks, made broadly accessible. Nucleic Acids Res. 45, D362D368. doi: 10.1093/nar/gkw937

Tanaka, K., Tsukahara, T., Yanagi, T., Nakahara, S., Furukawa, O., Tsutsui, H., et al. (2017). Bifidobacterium bifidum OLB6378 simultaneously enhances systemic and mucosal humoral immunity in low birth weight infants: a non-randomized study. Nutrients 9:195. doi: 10.3390/nu9030195

Tanca, A., Abbondio, M., Palomba, A., Fraumene, C., Manghina, V., Cucca, F., et al. (2017). Potential and active functions in the gut microbiota of a healthy human cohort. Microbiome 5:79. doi: 10.1186/s40168-017-0293-3

Untergasser, A., Cutcutache, I., Koressaar, T., Ye, J., Faircloth, B. C., Remm, M., et al. (2012). Primer3-New capabilities and interfaces. Nucleic Acids Res. 40:e115. doi: 10.1093/nar/gks596
Villot, C., Chen, Y., Pedgerachny, K., Chaucheyras-Durand, F., Chevaux, E., Skidmore, A., et al. (2020). Early supplementation of Saccharomyces cerevisiae boulardii CNCM I-1079 in newborn dairy calves increases IgA production in the intestine at 1 week of age. J. Dairy Sci. 103, 8615-8628. doi: 10.3168/jds. 2020-18274

Walker, D. G., and Lue, L. F. (2015). Immune phenotypes of microglia in human neurodegenerative disease: challenges to detecting microglial polarization in human brains. Alzheimers Res. Ther. 7:56. doi: 10.1186/s13195-015-0139-9

Walker, P. G., Constable, P. D., Morin, D. E., Drackley, J. K., Foreman, J. H., and Thurmon, J. C. (1998). A reliable, practical, and economical protocol for inducing diarrhea and severe dehydration in the neonatal calf. Can. J. Vet. Res. 62, 205-213.

Wang, K., Cao, G., Zhang, H., Li, Q., and Yang, C. (2019). Effects of Clostridium butyricum and Enterococcus faecalis on growth performance, immune function, intestinal morphology, volatile fatty acids, and intestinal microbiota in a piglet model. Food Funct. 10, 7844-7854. doi: 10.1039/c9fo01650c

Wang, S., Peng, Q., Jia, H. M., Zeng, X. F., Zhu, J. L., Hou, C. L., et al. (2017). Prevention of Escherichia coli infection in broiler chickens with Lactobacillus plantarum B1. Poult. Sci. 96, 2576-2586. doi: 10.3382/ps/pex061

Wiśniewski, J. R., Zougman, A., Nagaraj, N., and Mann, M. (2009). Universal sample preparation method for proteome analysis. Nat. Methods 6, 359-362. doi: $10.1038 /$ nmeth. 1322

Wu, W., Sun, M., Chen, F., Cao, A. T., Liu, H., Zhao, Y., et al. (2017). Microbiota metabolite short-chain fatty acid acetate promotes intestinal IgA response to microbiota which is mediated by GPR43. Mucosal Immunol. 10, 946-956. doi: 10.1038/mi.2016.114

Wu, Y., Wang, L., Luo, R., Chen, H., Nie, C., Niu, J., et al. (2021a). Effect of a multispecies probiotic mixture on the growth and incidence of diarrhea, immune function, and fecal microbiota of pre-weaning dairy calves. Front. Microbiol. 12:681014. doi: 10.3389/fmicb.2021.681014

Wu, Y., Wenju, Z., Hongli, C., and Qicheng, L. (2021b). Optimization of 3 strains of the compound microecological preparation for preventing calf diarrhea. J. Livestock Ecol. 42, 115-120.

Xin, H., Ma, T., Xu, Y., Chen, G., Chen, Y., Villot, C., et al. (2021). Characterization of fecal branched-chain fatty acid profiles and their associations with fecal microbiota in diarrheic and healthy dairy calves. J. Dairy Sci. 104, 2290-2301. doi: 10.3168/jds.2020-18825

Younis, G., Awad, A., Dawod, R. E., and Yousef, N. E. (2017). Antimicrobial activity of yeasts against some pathogenic bacteria. Vet. World 10, 979-983. doi: 10.14202/vetworld.2017.979-983

Zhang, X., Ning, Z., Mayne, J., Moore, J. I., Li, J., Butcher, J., et al. (2016). MetaProIQ: a universal metaproteomic approach to studying human and mouse gut microbiota. Microbiome 4:31. doi: 10.1186/s40168-016-0176-z

Zugel, U., and Kaufmann, S. H. E. (1999). Role of heat shock proteins in protection from and pathogenesis of infectious diseases. Clin. Microbiol. Rev. 12, 19-39.

Conflict of Interest: RL and HC were employed by Xinjiang Tianshan Junken Animal Husbandry Co., Ltd.

The remaining authors declare that the research was conducted in the absence of any commercial or financial relationships that could be construed as a potential conflict of interest.

Publisher's Note: All claims expressed in this article are solely those of the authors and do not necessarily represent those of their affiliated organizations, or those of the publisher, the editors and the reviewers. Any product that may be evaluated in this article, or claim that may be made by its manufacturer, is not guaranteed or endorsed by the publisher.

Copyright (C) 2022 Wu, Nie, Luo, Qi, Bai, Chen, Niu, Chen and Zhang. This is an open-access article distributed under the terms of the Creative Commons Attribution License (CC BY). The use, distribution or reproduction in other forums is permitted, provided the original author(s) and the copyright owner(s) are credited and that the original publication in this journal is cited, in accordance with accepted academic practice. No use, distribution or reproduction is permitted which does not comply with these terms. 